Research Article

\title{
Experimental and Numerical Studies on Vibration Modes and Transcranial Attenuation Characteristics in Unilateral Bone Conduction Hearing
}

\author{
Jia Li, ${ }^{1,2,3}$ Liujie Ren, ${ }^{2,3}$ Tongge $W u^{1}{ }^{1}$ Dongming Yin, ${ }^{2,3}$ Peidong Dai, ${ }^{2,3}$ Lifen Chen, ${ }^{1}$ \\ and Tianyu Zhang $\mathbb{D}^{1,2,3}$ \\ ${ }^{1}$ Department of Aeronautics and Astronautics, Fudan University, Shanghai, China \\ ${ }^{2}$ Department of FPRS, Eye \& ENT Hospital of Fudan University, Shanghai, China \\ ${ }^{3}$ ENT Institute, Eye \& ENT Hospital of Fudan University, Shanghai, China
}

Correspondence should be addressed to Tianyu Zhang; ty.zhang2006@aliyun.com

Received 24 October 2019; Accepted 28 April 2020; Published 1 June 2020

Academic Editor: Mohammad Rafiee

Copyright (C) $2020 \mathrm{Jia} \mathrm{Li} \mathrm{et} \mathrm{al.} \mathrm{This} \mathrm{is} \mathrm{an} \mathrm{open} \mathrm{access} \mathrm{article} \mathrm{distributed} \mathrm{under} \mathrm{the} \mathrm{Creative} \mathrm{Commons} \mathrm{Attribution} \mathrm{License,} \mathrm{which}$ permits unrestricted use, distribution, and reproduction in any medium, provided the original work is properly cited.

Bone conduction (BC) hearing devices have been used to improve hearing in patients with unilateral conductive hearing loss; however, the clinical results of improvement in the sound localization ability are still controversial. Transcranial transmission in BC may be an important factor affecting sound localization abilities. Transcranial or interaural attenuation, derived from energy attenuation during the $\mathrm{BC}$ process, is determined by the different transfer functions of multiple pathways and affected by the whole-head vibration modes. The purpose of this study is to analyze the frequency dependence of BC vibration modes of the whole head, the contribution of middle and inner ear pathways to BC hearing, and the relationship between transcranial attenuation results by dynamics measurement and hearing thresholds. Experimental studies of vibration modes and transcranial attenuation characteristics in BC are performed using scanning laser Doppler vibrometry (LDV) measurements on human cadaver heads. Differences in vibration modes between the excitation and contralateral sides are observed. Additionally, a multiscale human whole-head FE model, including the skull, bony outer ear, ossicular chains, and bony inner ear structures, is proposed to study the mechanism of BC in the human hearing system. After verifying the rationality of the FE model using mechanical impedance and frequency response data, the transcranial attenuation on the temporal bone surfaces and the middle ear structure is calculated in the FE model. Moreover, the vibration characteristics of bilateral ossicular chains and the cochlear bony wall are observed in the whole-head FM model to study their contributions to BC hearing. By analyzing the experimental and numerical results of the vibration modes and the frequency response of the whole head incorporating the ossicular chain and cochlear bony wall, the intrinsic relationship between the results of transcranial attenuation by 1D LDV, 3D LDV, and hearing threshold measurements is further investigated.

\section{Introduction}

Bone conduction devices (BCDs) can convert received sound into mechanical vibration; subsequently, the vibration is transmitted to the inner ear, thereby stimulating hair cells and producing auditory signals $[1,2]$. One purpose of unilateral BCD implantation for patients who have unilateral hearing loss is to form spatial hearing by cooperating with the healthy ear, thereby improving the abilities of sound localization and speech recognition in noise $[3,4]$. In past clinical studies, however, unlike the significantly improved sound localization abilities of patients who have bilateral conductive hearing loss through using bilateral BCDs, the clinical effectiveness is still controversial for unilateral hearing loss patients using unilateral BCDs [5-7]. Studies on auditory mechanics suggested that the intrinsic mechanism of these clinical outcomes was related to the different transmission characteristics between bone conduction (BC) and air conduction (AC) [8]. BC has multiple transmission pathways, including skull bone pathways [9], middle ear 
pathways $[10,11]$, and cerebrospinal fluid (CSF) pathways [12]. However, unlike AC, BC energy can transmit to the contralateral ear with small attenuations through wholehead vibration, which is called BC transcranial or interaural transmission, resulting in interference with $\mathrm{AC}$ hearing. Theoretically, the improvement in sound localization abilities can benefit from greater transcranial or interaural attenuation because of the smaller interference between $\mathrm{BC}$ hearing and $\mathrm{AC}$ hearing in the healthy ear. Therefore, the characteristics of transcranial attenuation in BC may be important factors affecting the sound localization abilities of patients with both normal AC- and BC-aided hearing, which must be studied in detail.

The transcranial attenuation of $\mathrm{BC}$ is the loudness difference between the excitation ear and contralateral ear [13]. It derives from the energy attenuation during vibration transmission processes in $\mathrm{BC}$. The excitation positions of BCDs are typically placed on the mastoid of the head, and the transcranial attenuation can be expressed as differences in transfer functions between the excitation points and cochleae of both sides of the head. Clinically, because the transcranial attenuation is much smaller $(0-15 \mathrm{~dB})$ compared with $\mathrm{AC}$ when measuring $\mathrm{BC}$ hearing thresholds in pure tone audiometry [14], it is necessary to apply auditory masking to nontest ears to avoid cross-hearing. The Hood plateau method, widely used in BC hearing threshold tests, is based on this transcranial attenuation theory $[15,16]$.

Different transfer functions of multiple pathways determine the frequency dependence of transcranial attenuation characteristics. Past clinical and experimental studies have shown that the audiometry results by hearing thresholds measurements and laboratory results by dynamics measurements are not entirely consistent, and these results support mutually $[14,17,18]$. To be more specific, in the low frequency, the transcranial attenuation results measured by one-dimensional laser Doppler vibrometry (LDV) are near consistent with the three-dimensional ear attenuation results, but they are both less than the hearing threshold results for about $5 \mathrm{~dB}$. In the middle frequency, the one-dimensional LDV results, three-dimensional LDV results, and hearing thresholds results are inconsistent with each other. In the high frequency of above $2000 \mathrm{~Hz}$, they turn to be all consistent and have the same upward trends. The inconsistent transcranial attenuation results by different measurements arise the consideration of its inherently relevant whole-head vibration mode at different frequencies.

The $\mathrm{BC}$ process of the cochlea involves various biological tissues, and based on the anatomical structure of the head, it is generally believed that its transmission pathways can be decomposed into bone pathways that transmit the majority of vibration energy [1], middle ear pathways in which the middle-ear structural resonance is responsible for the prominent peak shown at $1.5-2 \mathrm{kHz}$ [19], and CSF pathways in which audio-frequency sound pressures can be conveyed to the cochlea and stimulated [20]. In terms of structural dynamics and fluid mechanics, $\mathrm{BC}$ vibration transfer functions and transcranial attenuation are closely related to the vibrational modes of the skull in different frequencies. The human skull comprises a dense cortical bone, between which is a liquid-filled nasal bone with skin and subcutaneous tissue on the one side and fluid (CSF) and brain tissues on the other side. In addition, the bone at the bottom of the skull where the inner ear is located is different from the skull, and the bone structure is thicker and denser. Furthermore, the skull is not a single bone structure, but a fusion of several parts and sutures. Owing to its complexity, modeling studies have thus far provided only a limited understanding of BC sound transmission in the skull. In past experiment studies, the vibration mode of the skull has been estimated by measuring and comparing the amplitude and phase response of a few points on the surface of the skull [14]. The results indicated that when the $\mathrm{BCD}$ excitation position is on the mastoid, with the increase in the frequency range from 0.1 to $10 \mathrm{kHz}$, the skull exhibits different vibration modes. At low frequencies, i.e., below the resonant frequency of the mechanical point impedance of the skull $(150-400 \mathrm{~Hz})$, the skull vibrates as a whole, resembling a rigid body. Subsequently, at middle frequencies up to $1 \mathrm{kHz}$, it vibrates like a mass-spring system. At high frequencies, i.e., at the skull base, $\mathrm{BC}$ energy transmits by compression waveforms, but in the cranial vault, it transmits by wave-like movements. Bone conducted hearing caused by rigid body and compression modes is called inertia and compressed BC, respectively. The inertia $\mathrm{BC}$ is generally speculated to be caused by the lag effect of the lymph fluid relative to the cochlear bone structure and the ossicular chain relative to the middle ear cavity $[19,21]$. The compressed BC is generally speculated to be caused by relative movement of the cochlear bony wall, which can cause pressure gradients in the lymph [22].

In this study, we investigate the frequency dependence of $\mathrm{BC}$ vibration modes, the middle and inner ear contribution to $\mathrm{BC}$ hearing, and the relationship between transcranial attenuation results measured by $1 \mathrm{D}$ and $3 \mathrm{D}$ LDV and hearing thresholds. Detailed information of the vibration mode of the skull at different frequencies is first obtained using scanning LDV. Differences in vibration modes between the excitation and contralateral sides are observed, and the transcranial attenuation at the temporal bone surfaces is calculated. In addition, a finite element (FE) model of the human whole head comprises the cranial bone, middle ear, outer ear, and brain is established. After verifying the rationality of the FE model using mechanical impedance and frequency response data, the vibration modes and transcranial attenuation at the temporal bone surfaces are calculated to compare with the experiment results of this study and those of others. Moreover, the frequency response characteristics of bilateral ossicular chains and the cochlear bony wall are observed in the wholehead FM model. By analyzing the experimental and numerical results of whole-head vibration modes, together with the frequency response of the whole head incorporating the ossicular chain and cochlea bony wall, the intrinsic relationship between the results of transcranial attenuation by 1 D LDV, 3-D LDV, and hearing thresholds measurements is further investigated. 


\section{Materials and Methods}

\subsection{Whole-Head Vibration Measurement}

2.1.1. Human Cadaver Head Preparation. Two fresh cadaver full heads (two male subjects, aged 55 and 60, one specimen for preliminary experiment) were used in the measurements. The cadaver full-head specimens were obtained from the Department of Pathology, Fudan University, following appropriate guidelines and procedures for obtaining and using human tissues. The full cadaver heads were intact during the autopsy. On the day of the experiment, the full cadaver heads were allowed to thaw at room temperature and subsequently immersed in saline solution $(0.9 \%)$ for approximately $3 \mathrm{~h}$ before beginning the experiments. Experiments were performed within two months postmortem.

Before the experiment, the cadaver heads were first removed from a deep freezer of $-18^{\circ} \mathrm{C}$. Subsequently, surgery was performed to expose the roof of the skull, forehead, and temporal bone. The measured areas of the skull, forehead, and roof surfaces were approximately 2, 1.5, and $3 \mathrm{dm}^{2}$, respectively. To obtain a better laser reflection effect, the exposed surfaces were covered with reflective spray.

The heads were stably placed on a soft basement to ensure that all parts could move freely. Therefore, the system's resonant frequency in the experiment was the natural frequency of the head itself, rather than the system containing the neck boundary conditions, and the vibration modes were only of the head, as illustrated in Figure 1.

2.1.2. BC Excitation Methods. A B71 BC electromagnetic transducer or BC vibrator (Radioear Corporation, USA) was placed on the mastoid fixed by two 4-mm fixtures on both sides (Figure 1). The fixture stability was verified by resonance frequency analysis, as described previously [9]; a loose implant would cause a significant decrease in impedance. The vibrator was powered by a built-in signal generator of the scanning LDV (PSV-500 Polytec GmbH, Germany). Two types of signals were provided: (1) sweep signals (voltage loads at 3,5 , and $7 \mathrm{~V}$ ) ranging from 0.1 to $10 \mathrm{kHz}$ and (2) single-frequency signals (voltage loads at $5 \mathrm{~V}$ ) at frequencies of $250 \mathrm{~Hz}, 500 \mathrm{~Hz}, 1 \mathrm{kHz}, 1.5 \mathrm{kHz}, 2 \mathrm{kHz}, 3 \mathrm{kHz}, 4 \mathrm{kHz}$, $5 \mathrm{kHz}$, and $6 \mathrm{kHz}$. The B71 vibrator was successively plated on the left and right of the temporal bone; therefore, two sets of measurements were conducted for each specimen.

We used different voltage loads at 3, 5, and $7 \mathrm{~V}$ on the vibrator to obtain a suitable voltage input and good signalto-noise ratio measurement results. Besides, the velocity responses of the skull surface under different voltages indicated that, within these voltage excitation ranges, the response curve under B71 transducer excitation had a good linearity. Additionally, during the experiment, the vibrator did not reach its maximum output power; otherwise, the stabilities of the results would be affected.

2.1.3. Vibration Acquisition. Vibration responses were measured using the scanning LDV system. The vibration of four areas of each head was measured, including surfaces of the ipsilateral side, contralateral side, roof of the head, and forehead. Before starting the measurements, measurement areas and data acquisition points were selected on the surface depending on the shape and size; therefore, a series of measuring grids was formed (Figure 1). Subsequently, the measurement system was verified to ensure that the velocity data at each measuring point could be measured accurately. This verification was performed because the shape of the skull surface was irregular, and some of the measurement points were low in reflective intensity.

The transfer functions of the average velocity between the four areas were calculated to estimate the transcranial attenuation. Subsequently, the measured displacement and phase of the areas were mapped to an entire 3D skull model, and the vibration modes of the skull at various frequencies are discussed. The duration of the experiments was $60 \mathrm{~min}$ on average and did not exceed $80 \mathrm{~min}$ per head.

2.1.4. Vibration Mode Visualization. The vibration information of the four measuring surfaces and the voltage information of the vibrator were used to form the vibration modes of the entire head. First, the motion data of each surface were synchronized by the voltage signals. Subsequently, the displacement information was mapped to a virtual head model, in which the measurement data of four areas were geometrically projected according to the direction of the measurement. Hence, the displacement information was transformed into the motion information of the mapping point on the whole-head model.

\subsection{FE Model Analysis}

2.2.1. Geometry Model and Mesh of Human Whole Head. The FE model of the whole head was established by the reconstruction of $\mathrm{CT}$ image of the human head (male subject, aged 35, no ear diseases). Firstly, the grey information of the head was obtained by CT image with a scanning layer thickness of $0.5 \mathrm{~mm}$. Then, the CT images were processed for thresholding, edge extraction, and surface reconstruction in Mimics (Mimics ver12.3, Materialise NV). The geometric contours of the skull and the contents are therefore obtained and output in the form of point cloud. After that, the point cloud data were imported into Geomagic Studio (Geomagic Studio ver2012, Geomagic Inc.), and the reconstructed surface of the human skull was smoothed and cleaned up for artifacts to acquire a geometric model.

Within the meshing process, to establish a balance between mesh quality and computation resources, the human skull model was manually partitioned based on the anatomical section, as shown in Figure 2(a). Taking advantage of the anatomical partition, the frontal bone, parietal bones, and occipital bone could have relatively large element size to accommodate limited computational resource. However, the sphenoid bone, facial skeleton (13 bones not including mandible), and ethmoid bone could have medium element sizes to represent the sophisticated geometric features. Last but not least, both temporal bones would be assigned with 


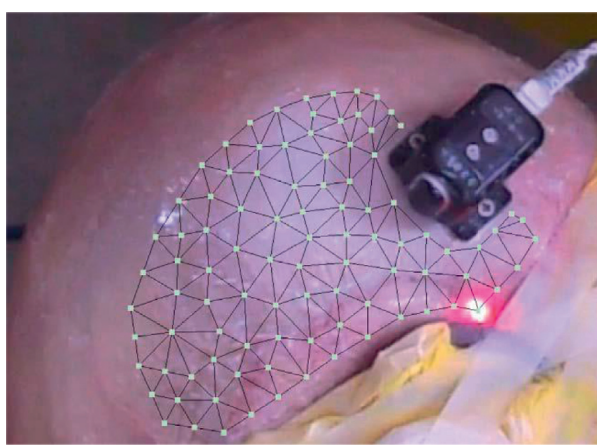

(a)

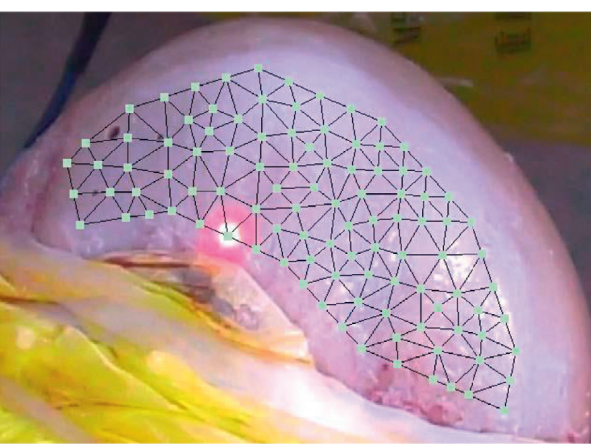

(b)

Figure 1: BC excitation and vibration acquisition by scanning LDV. (a) A B71 BC vibrator was placed on the mastoid fixed by two nails. The exposed surface was covered by reflective spray, and the measuring grid is shown as white dots and grey lines. The red dot shows the data acquisition point by scanning LDV. (b) Measuring grid and acquisition points of the contralateral temporal bone surface.

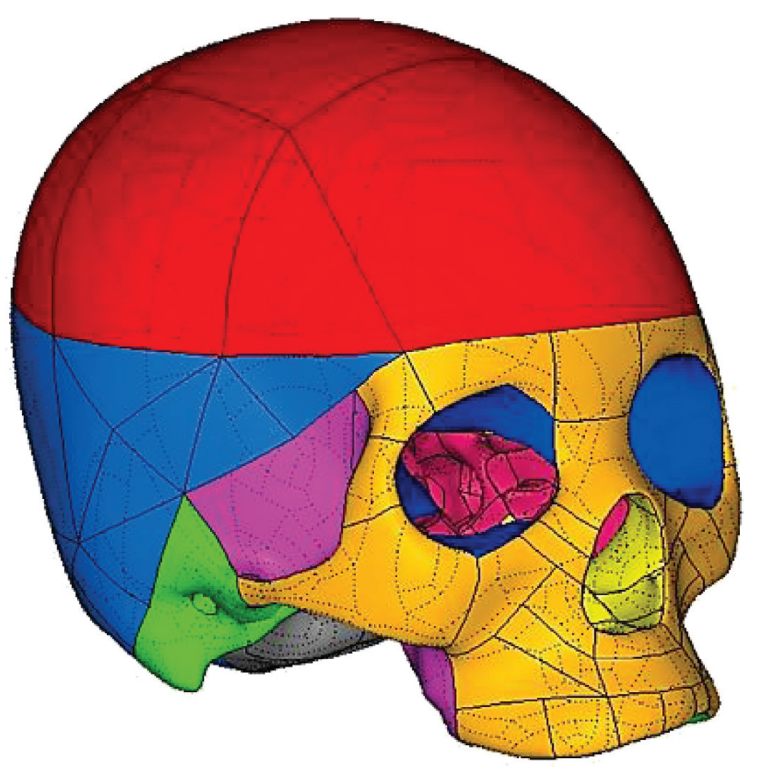

(a)

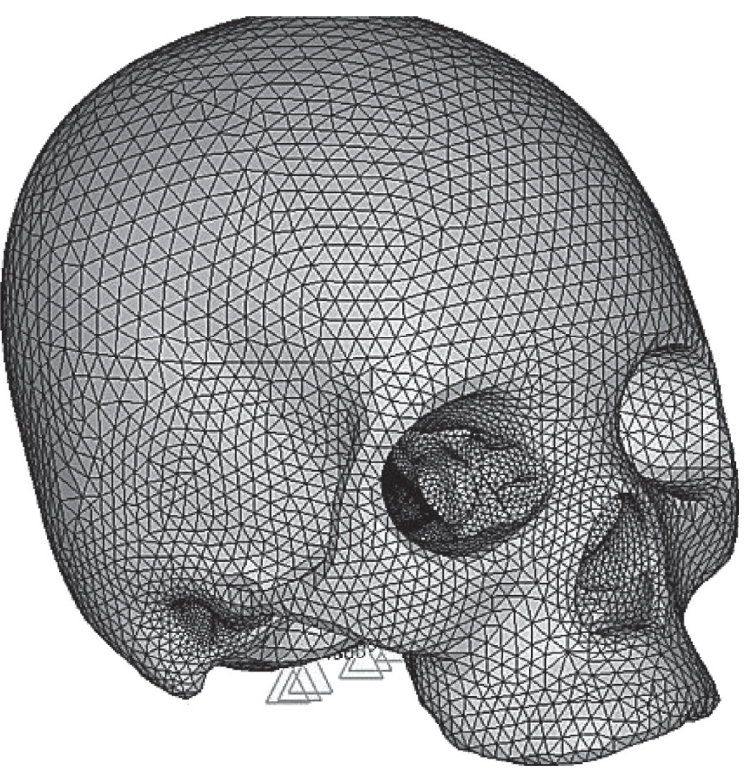

(b)

Figure 2: Continued. 


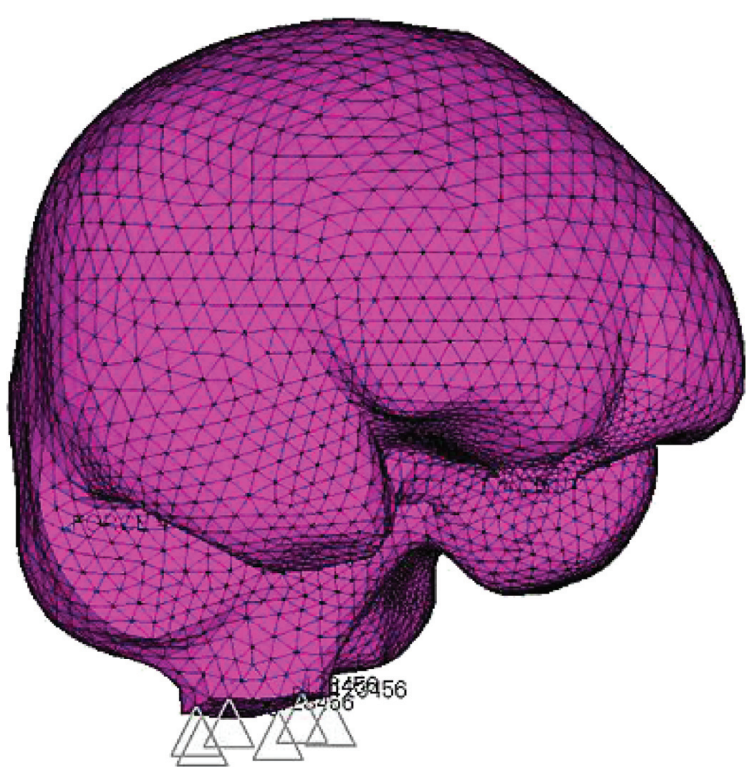

(c)

Figure 2: Geometry model and mesh. (a) The geometry model of the skull manually partitioned based on the anatomic section. The frontal bone, parietal bones, and occipital bone (red, blue, and grey areas) were discretized with a more significant element size compared to the temporal bone (green area). (b) Volume mesh of the human skull indicates the transition of element size on different regions of the human skull and dense mesh on the temporal bone to accommodate middle ear and bony inner ear structures. Grey triangles on the edge of the foramen occipital magnum indicate the fixed boundary condition. (c) Volume mesh of the cranial soft tissue as a homogeneous model. The surface of the cranial soft tissue shares nodes with the interior surfaces of the cortical bone of the human skull. Grey triangles on the edge of the foramen occipital magnum represent the fixed boundary condition.

the smallest element size to generate reasonable mesh transition into the middle ear and bony inner ear structures. At the end of the meshing process, the three-dimensional human skull model was meshed with tetrahedral elements, as shown in Figure 2(b), whose size varies from $0.5 \mathrm{~mm}$ (at the temporal bone nearby the bony ear canal) to $6 \mathrm{~mm}$ (at the flat region on the frontal bone).

The cranial soft tissue geometric model was constructed based on the interior surfaces of the cortical bone of the human skull. The interior surfaces of the skull were extracted and patched to encapsulate a connected volume, which represented a homogeneous cranial soft tissue model. This cranial soft tissue volume was then discretized by tetrahedral elements sharing all surface nodes with interior surface nodes of the skull, as shown in Figure 2(c). The constructed FE model of the whole head has not incorporated the head's outer skin.

As the CT resolution of the whole head is not high enough to reconstruct the middle ear part, geometric models of middle ear structures including tympanic membrane, auditory ossicles, and the bony inner ear structure were established by using the method of continuous tissue sections at the thickness of $0.05 \mathrm{~mm}$ for a higher resolution.

The positions of the ear canal, middle ear cavity, and inner ear bone labyrinth were obtained from CT image data, which constitute the inner surface of the temporal bone. Together with the outer surface of the skull, they formed closed curved surface. In the FE modeling process, this closed surface was first discretized into surface mesh, and then solid elements were generated. The internal surface of the middle ear cavity was manually developed (Geomagic ver2012) and meshed (HyperMesh ver12.0). The middle ear cavity surface mesh was positioned inside the temporal bones to connect the bony outer ear canal and the bony inner ear structures. At the connection region between the bony outer ear canal and the middle ear cavity, surface elements at the tympanic membrane (TM) position were removed, and connected nodes share all degrees of freedom among the ear canal, the TM, and the middle ear cavity, as shown in Figures 3(a)-3(c).

The bony inner ear structure was discretized into surface mesh, then positioned inside the temporal bone, and created cavities to mimic the anatomical cochlea, vestibule, and semicircular canals. However, surface elements at the oval window and round window were removed at the connection region between the middle ear cavity and the bony inner ear structure, as shown in Figure 3(a). At the stapes footplate, the middle ear cavity is coupled with the bone labyrinth by nodes sharing all degrees of freedom among the middle ear cavity, stapes footplate, and the oval window.

Inside the middle ear cavity, TM consisted of pars tensa and pars flaccida in a concave shape and was discretized using shell elements, whose perimeter nodes were shared with the end of the outer ear canal. The TM, three ossicles, two joints, six ligaments, and two tendons' geometric models (Table 1) were meshed by tetrahedral elements, positioned based on anatomical data. Besides, in addition to the coupling between TM and ear canal and the coupling between stapes footplate and inner ear, the ossicles were coupled with the middle ear cavity by two muscles (tensor tympani muscle 


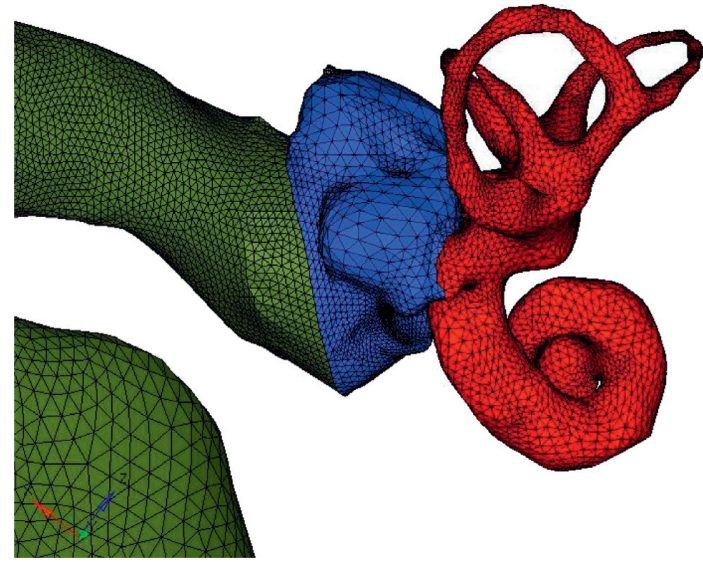

(a)

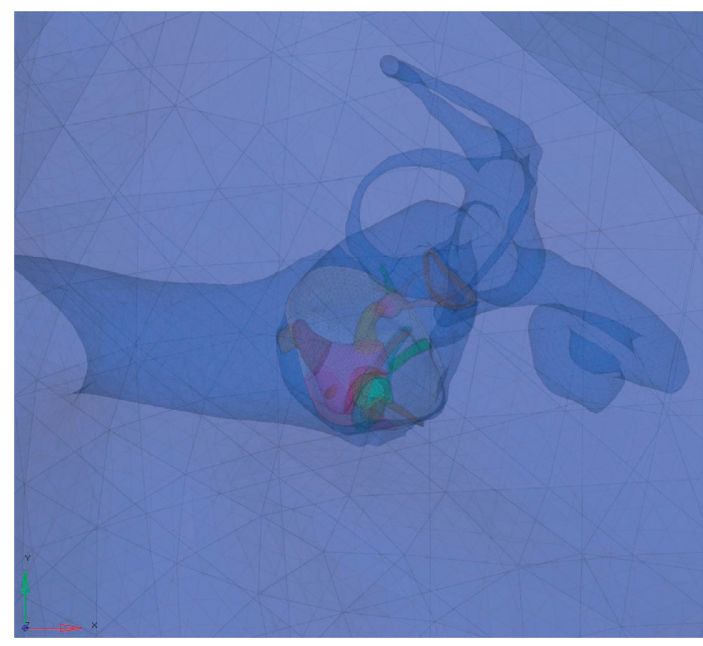

(c)

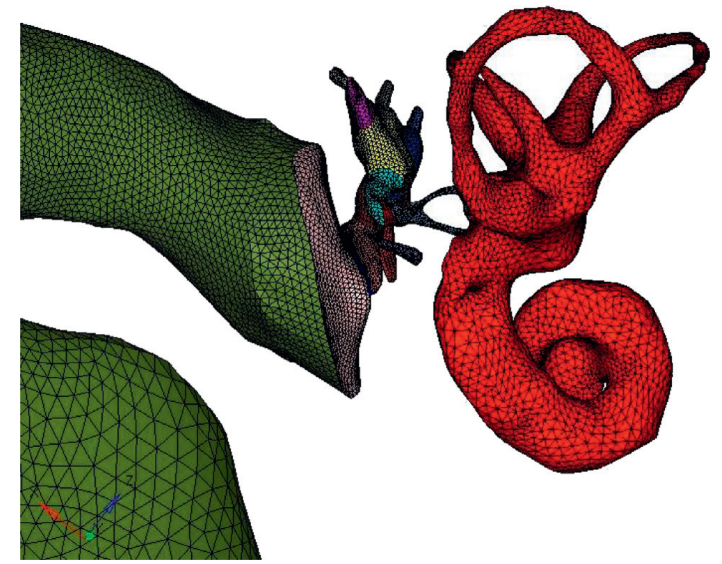

(b)

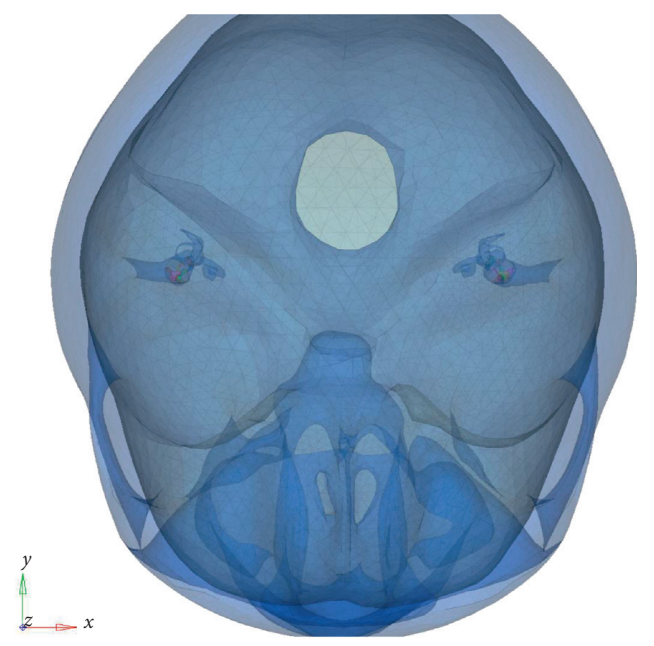

(d)

Figure 3: Geometry model and mesh of ear canal, middle ear, inner ear, and the finally coupled model. (a) The spatial connection of the bony outer ear canal (green), the middle ear cavity (blue), and the bony inner structure (red). The volume mesh of the human skull was hidden to show this microstructure. (b) The spatial connection of the bony outer ear canal (green), the middle ear structures (multiple colors), and the bony inner ear structure (red). The middle ear cavity was hidden, while some ligaments have one end connected to the surface of the middle ear cavity. (c) The spatial connection of the bony outer ear canal (blue), the middle ear cavity (blue), the middle ear structures (multiple colors), and the bony inner structure (blue). The volume mesh of the human skull (blue) was made transparent to show this microstructure. (d) The finally coupled model of the whole head.

and stapedius) and six ligaments to ensure the reasonableness, as shown in Figures 3(b)-3(d).

\subsubsection{Material Parameters of the FE Model. The human skull} comprised cortical and trabecular bones. However, it was considered as an isotropic homogeneous linear elastic material when the modulus was determined by numerical experiments. Four different moduli were assigned (7300, 9000, 10000 , and $15000 \mathrm{MPa}$ ), and the first three natural frequencies of the human skull were tabulated for comparison. With the increase in Young's modulus, the first three modes improved, which was consistent with the essential characteristics of the skull dynamics. With the assistance of experimental natural frequencies, Young's modulus of the skull was calibrated as $10,000 \mathrm{MPa}$ (Table 2). Additionally, the cranial soft tissue was recognized as an isotropic homogeneous linear elastic material, whose Young's modulus was $0.003 \mathrm{MPa}$ [23]. The density of the human skull was acquired using a similar calibration technique as Young's modulus of the human skull. Three density values were assumed $\left(0.8,1.2\right.$, and $\left.1.6 \mathrm{~g} / \mathrm{cm}^{3}\right)$, and the transcranial attenuations of the temporal bone were calculated. Based on the frequency of the first valley of the experimental transcranial attenuation, the density of the human skull was linearly interpolated to be near $1.0 \mathrm{~g} / \mathrm{cm}^{3}$, while the density of the cranial soft tissue was $1.0412 \mathrm{~g} / \mathrm{cm}^{3}$ according to a reported value [24]. Furthermore, Poisson's ratios of the human skull and cranial soft tissue were 0.3 [25] and 0.33 [26], respectively.

The damping ratio of the human whole-head structure was calibrated based on the amplitude of the first valley of the experimental transcranial attenuation. Linear extrapolation was performed (numerical experiments values: $2 \%$, $3.5 \%$, and $5 \%$ ), and with the increase in the damping 
TABLE 1: Material properties of middle ear structure components.

\begin{tabular}{|c|c|c|}
\hline Component & $\begin{array}{l}\text { Young's modulus } \\
(\mathrm{MPa})\end{array}$ & Density $\left(\mathrm{kg} / \mathrm{m}^{3}\right)$ \\
\hline TM pars tensa & $3.5 \times 10^{1}$ & $1.2 \times 10^{3}$ \\
\hline TM pars flaccida & $1.0 \times 10^{1}$ & $1.2 \times 10^{3}$ \\
\hline Malleus head & $1.41 \times 10^{4}$ & $2.55 \times 10^{3}$ \\
\hline Malleus neck & $1.41 \times 10^{4}$ & $4.35 \times 10^{3}$ \\
\hline Malleus handle & $1.41 \times 10^{4}$ & $3.7 \times 10^{3}$ \\
\hline Incus body & $1.41 \times 10^{4}$ & $2.36 \times 10^{3}$ \\
\hline Incus short process & $1.41 \times 10^{4}$ & $2.26 \times 10^{3}$ \\
\hline Incus long process & $1.41 \times 10^{4}$ & $5.08 \times 10^{3}$ \\
\hline Stapes & $1.41 \times 10^{4}$ & $2.2 \times 10^{3}$ \\
\hline Incudomalleolar joint & $1.41 \times 10^{4}$ & $3.2 \times 10^{3}$ \\
\hline Incudostapedial joint & $6.0 \times 10^{-1}$ & $1.2 \times 10^{3}$ \\
\hline Manubrium & $4.7 \times 10^{3}$ & $1.0 \times 10^{3}$ \\
\hline $\begin{array}{l}\text { Superior mallear } \\
\text { ligament }\end{array}$ & 4.9 & $2.5 \times 10^{3}$ \\
\hline Lateral mallear ligament & 1.0 & $2.5 \times 10^{3}$ \\
\hline $\begin{array}{l}\text { Anterior mallear } \\
\text { ligament }\end{array}$ & 2.1 & $2.5 \times 10^{3}$ \\
\hline $\begin{array}{l}\text { Superior incudal } \\
\text { ligament }\end{array}$ & 4.9 & $2.5 \times 10^{3}$ \\
\hline $\begin{array}{l}\text { Posterior incudal } \\
\text { ligament }\end{array}$ & $6.5 \times 10^{-1}$ & $2.5 \times 10^{3}$ \\
\hline $\begin{array}{l}\text { Stapedial annular } \\
\text { ligament }\end{array}$ & $1.0 \times 10^{-1}$ & $2.5 \times 10^{3}$ \\
\hline Tensor tympani tendon & 2.6 & $2.5 \times 10^{3}$ \\
\hline Stapedial muscle tendon & $5.2 \times 10^{-1}$ & $2.5 \times 10^{3}$ \\
\hline
\end{tabular}

TABLE 2: Relationship between Young's modulus of bone tissue and modal frequency.

\begin{tabular}{lccc}
\hline $\begin{array}{l}\text { Young's } \\
\text { modulus }\end{array}$ & $\begin{array}{c}\text { 1st-order } \\
\text { modal }\end{array}$ & 2nd-order modal & 3rd-order modal \\
\hline $7,300 \mathrm{Mpa}$ & $213.47 \mathrm{~Hz}$ & $218.66 \mathrm{~Hz}$ & $471.39 \mathrm{~Hz}$ \\
$9,000 \mathrm{Mpa}$ & $237.02 \mathrm{~Hz}$ & $242.79 \mathrm{~Hz}$ & $523.41 \mathrm{~Hz}$ \\
$10,000 \mathrm{Mpa}$ & $249.84 \mathrm{~Hz}$ & $255.92 \mathrm{~Hz}$ & $551.72 \mathrm{~Hz}$ \\
$15,000 \mathrm{Mpa}$ & $306.00 \mathrm{~Hz}$ & $313.44 \mathrm{~Hz}$ & $675.72 \mathrm{~Hz}$ \\
\hline
\end{tabular}

coefficient, the transcranial attenuation curve tended to move upward. An $8 \%$ damping coefficient was used as the global damping in this model.

The material properties (modulus and density) of the middle ear structures were adopted from previous results by Gan et al. (Table 1) [27]. Poisson's ratio for all components was 0.3.

2.2.3. Boundary Condition. In this study, the inner ear lymph is not included. Therefore, to simulate the influence on the ossicular chain, the effect of the inner ear lymph fluid was equivalent to spring and damping system acting on the stapes footplate, developed by our previous studies [28]. The spring-mass-damping system consisted of 137 link elements in the contact surface of the stapes and the inner ear lymph fluid. To each, the cross-sectional area is $1 \mathrm{~mm}^{2}$, the length is $\sqrt{3} \mathrm{~mm}$, the mass is $1.86 \times 10^{-7} \mathrm{~kg}$, and the damping ratio is $1.1 \times 10^{-6} \mathrm{Ns} / \mathrm{mm}$. One end of the link element was fixed, while the other end was connected to the stapes footplate (Figure 4).

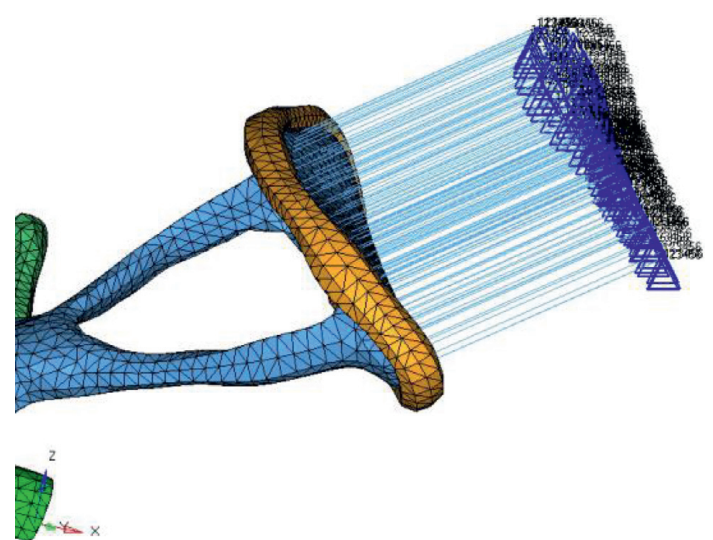

FIgURE 4: Stapes footplate and equivalent spring-mass-damping system FE models. Blue tetrahedral elements indicate stapes, while yellow ones indicate stapedial annular ligament. Light blue links elements, and dark blue triangles represent the spring-massdamping system and corresponding fixed ends, respectively.

The displacement (Dirichlet's) boundary condition for the human whole-head model was applied on the edge of the foramen occipital magnum, as shown in Figure 2(b), whose perimeter nodes were fixed for all degrees of freedom. The force (Neumann's) boundary condition for bone conduction stimulation was applied at the mastoid process of the left temporal bone, which was a harmonic pressure loading of $228.66 \mathrm{~Pa}$ on $43.73 \mathrm{~mm}^{2}$ surface of the human skull, to be consistent with the excitation method of the B71 transducer in the experimental study. The exciting force amplitude is $10 \mathrm{mN}$ in total and included in the force output range in the past $B C$ experiments studies using B71 transducer $[29,30]$. However, the harmonic pressure loading to mimic AC was placed on the TM shell elements with a magnitude of $0.632 \mathrm{~Pa}$ (equivalent $90 \mathrm{~dB}$ sound level).

2.2.4. Validation of FE Model of the Whole Head. The FE model of a human whole head with middle ear structures comprised 718,525 elements and 152,663 nodes. Each solving process consumed $24 \mathrm{~h}$ (a CPU equipped with $8 \mathrm{~GB}$ shared memory was used). The dynamic responses under $B C$ and AC stimuli were analyzed separately by a harmonic analysis module (ANSYS ver16.2). During the solving process, the frequency range for both $\mathrm{BC}$ and $\mathrm{AC}$ harmonic pressure loading was $200-8000 \mathrm{~Hz}$ and divided by 79 steps.

To validate our multiscale human whole-head FE model, the mechanical impedance of the human skull was evaluated at the simulation nodes and demonstrated a sufficient similarity compared with previous experimental results [31] (Figure 5). In the low- and high-frequency ranges, the maximum difference between the FE model and experimental results was approximately $5 \mathrm{~dB}$. In the middle-frequency range, the FM model and experimental data were almost identical. Because the experimental results were measured at the posterior caudal part of the temporal bone, which was close to the $\mathrm{BC}$ stimulation nodes, we concluded that our FE model could quantitatively simulate the $\mathrm{BC}$ process of a dry human head with satisfactory accuracy. 


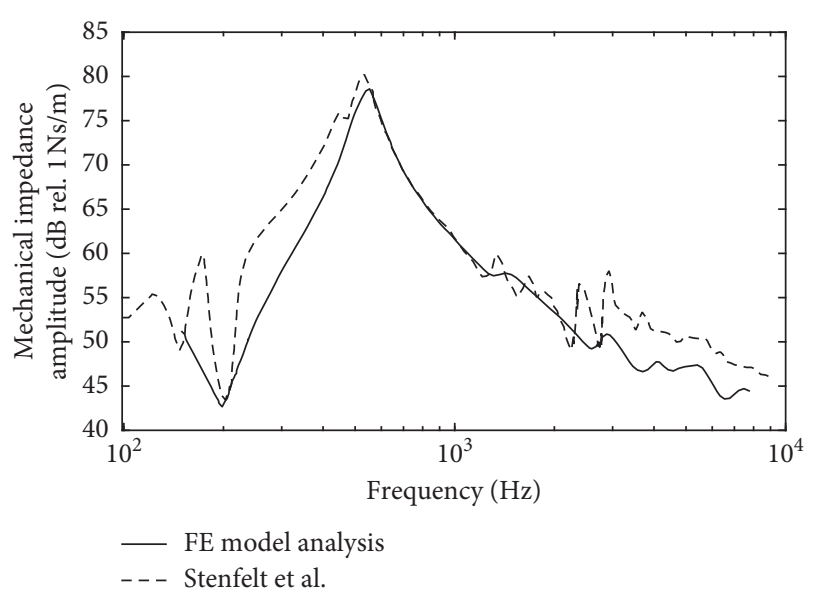

FIGURE 5: Magnitude of mechanical impedance at the stimulation point in the FE model and experimental results [31]. The mechanical impedance was evaluated by the ratio of the total external force to the average velocity of the same nodes; subsequently, the magnitude was obtained.

Additionally, the frequency response between the force applied to the mastoid and the acceleration response at the cochlear promontory curves was calculated from the FE model and compared with previous studies [14]. The position of the excitation point was above the external ear canal, with a distance of approximately $2 \mathrm{~cm}$, and the excitation direction was along the left-to-right direction of the head. The frequency response was extracted along three vertical directions from the $X$-, $Y$-, and $Z$-directions. The measurement directions of the ipsilateral and contralateral cochleae were as follows: $X$ direction-towards the middle of the head, $Y$ direction - towards the top of the head, and the $Z$ direction-towards the front of the head. As shown in Figure 6, the acceleration responses of the $X$-, $Y$-, and $Z$ directions declined before $1000 \mathrm{~Hz}$ and subsequently exhibited the same upward trend after $1000 \mathrm{~Hz}$. The results exhibited consistency compared with the experiment studies, indicating the reliabilities of the model.

To validate the multiscale human whole-head FE model, the displacement of TM under AC stimulation was evaluated and compared with previous computational results [27] (Figure 7). Two computational results demonstrated a typical plateau before $1 \mathrm{kHz}$ and decreased in the same manner with increasing frequency after $1 \mathrm{kHz}$. Furthermore, two FE models exhibited a relatively small discrepancy at the end of the plateau region, which might occur owing to the skull and cranial soft tissues in the new human whole-head FE model. With an 8\% damping ratio, the skull and cranial soft tissues would dissipate a portion of the stimulation energy, primarily at the low-frequency range.

Besides, the developed FE model was validated by comparing the frequency response of the TM and stapes footplates under BC with published experimental data [32]. The velocities of the TM and stapes footplate are relative to the velocity of the bone close to the TM and the promontory of the cochlea in the temporal bone and measured in the same direction as the TM and stapes footplate motion.

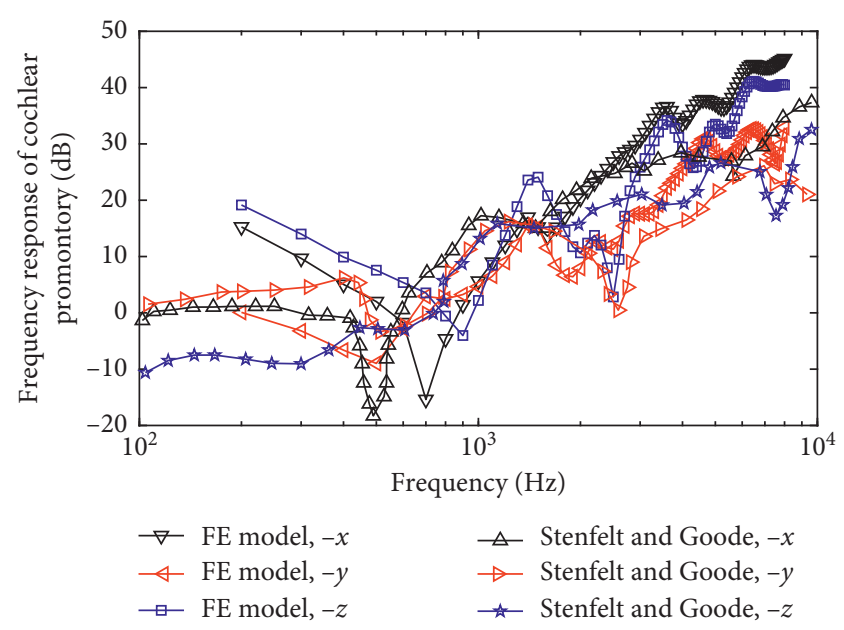

FIgURE 6: Frequency response of cochlear promontory by the FE model and experimental studies [14].

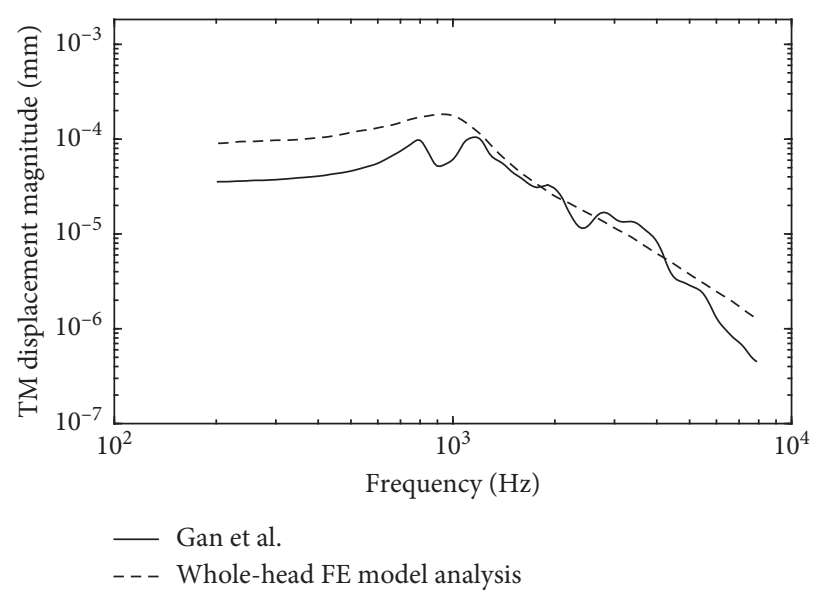

FIgURE 7: Magnitude of displacement at the concaved center of TM under AC stimulation from our multiscale human whole-head FE model (dashed line) and the middle ear FE model developed by Gan et al. [27] (solid line).

Relative velocity $V^{\text {rel }}$ of the TM and stapes footplate is, respectively, calculated as $V_{\mathrm{TM}}$ divided by $V_{\text {bone }}$ and $V_{\mathrm{ST}}$ divided by $V_{\text {promontory }}$. As shown in Figure 8, the TM and stapes footplate motion with $\mathrm{BC}$ stimulation was near $0 \mathrm{~dB}$ under $600 \mathrm{~Hz}$. At about $800 \mathrm{~Hz}$, the whole-head FE model results showed a certain gap with the average results of experiments results. After inspection of the individual results at this frequency of experimental data, some individuals with the same degree of peak were found. Subsequently, the velocities of TM and stapes footplates exhibited the same upward trend after $1000 \mathrm{~Hz}$. After reaching a peak at about $1500 \mathrm{~Hz}$, they all showed a downward trend. The results exhibited consistency compared with the experiment studies, indicating the reliabilities of the model. In conclusion, under either a BC or AC harmonic pressure stimulation, our multiscale human whole-head FE model was validated and demonstrated good agreement with 


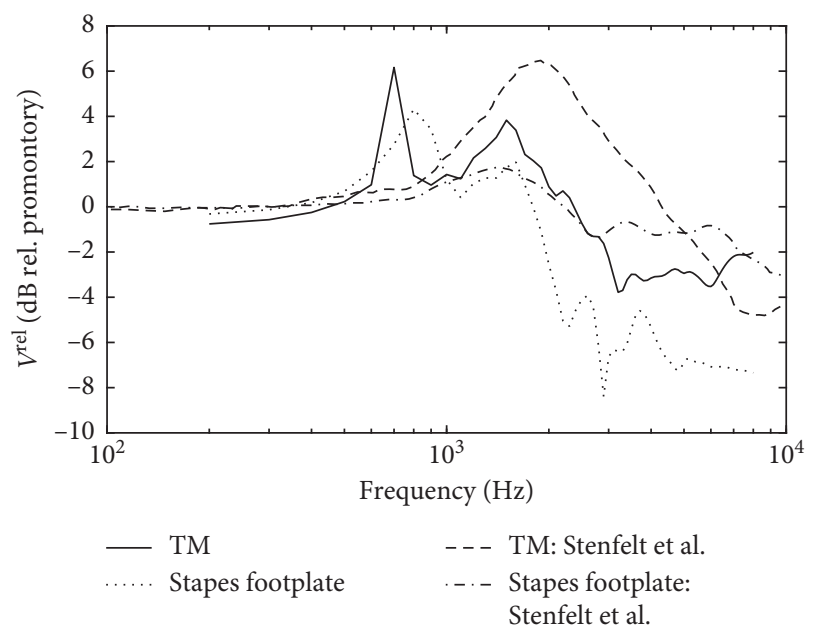

FIgURE 8: Comparison of TM and stapes footplate motion with BC stimulation from our multiscale human whole-head FE model (solid line and dotted line) and the experimental data by Stenfelt et al. (dashed line and dash-dot line) [32].

existing experimental and computational results in a wide range of frequencies.

\section{Results}

3.1. Vibration Modes of the Whole Head Using Scanning LDV Measurement. The vibration information of the four different regions (excitation side, contralateral, cranial roof, and forehead surfaces) of the skull under the same excitation conditions was obtained using scanning LDV (Figures 9-12). Additionally, by postprocessing these experimental results, we obtained different vibration modes of the skull surface under an overall vibration morphology (Figure 13).

Figures 9 and 10 show the vibration responses of the temporal bone surface of the excitation and contralateral sides at different frequencies, respectively. As shown in Figure 9(a), at $250 \mathrm{~Hz}$, the response presented an overall movement along the direction of the stimulus, and the amplitudes at different positions were almost the same. Figure 10(a) shows that the contralateral side of the temporal bone surface exhibits the same properties. The cranial roof and forehead surface were measured in the vertical direction. They moved in a flat form, which was consistent with the swing-like movement modes of the whole head, as shown in Figures 11(a) and 12(a). These proved that the whole head exhibited a rigid-body movement (Figure 13(a)).

In the frequency range of 500 to $1500 \mathrm{~Hz}$, the excitation side of the $\mathrm{BC}$ transducer no longer moved in the same phase, as shown in Figures 9(b)-9(d); however, the phase difference was not sufficiently significant to reach the wavelength distance in the measurement area. The contralateral temporal bone surface is still primarily in the form of planar swing, as shown in Figures 10(b)-10(d). And with the frequency increase, the regional phase in the bilateral temporal bone difference increased gradually, indicating that the wave-like motion is increasing (Figure 13(b)).
At frequencies above $2000 \mathrm{~Hz}$, the bilateral temporal bone surface showed more local motions, and the wavy motion was more significant (see Figures 9(f)-9(i) and Figures 10(f)-10(i)), suggesting that the cochlear volume and the relative motion of the inner wall were larger. Additionally, the local movement of the cranial roof and forehead surfaces owing to the thin structure, compared with the bilateral temporal bone surfaces, was more intense (see Figures 11(f)-11(i), Figures 12(f)-12(i), and Figure 13(c)).

3.2. Vibration Modes of the Whole Head Using FE Model Analysis. The displacement of the human skull surface nodes under BC stimulation was evaluated and visualized using the FM model. As shown in Figures 14(a) and 14(b), at $250 \mathrm{~Hz}$, on the surfaces of the ipsilateral and contralateral temporal bones and nearby bony tissues, the magnitude of the displacements increased with the distance to the fixed nodes. The linear relationship between the displacement magnitude and the distance to the fixed nodes revealed rigidbody vibrations at both sides of the human skull at low frequencies. Hence, at low frequencies, the human whole head was dominated by a rigid-body vibration mode in the FE model, consistent with the previous experimental results (Figure 13(a)). It is noteworthy that no fluctuations occurred in both sides.

At $1500 \mathrm{~Hz}$, on the ipsilateral parietal bone, the displacement magnitude increased with the distance to the fixed nodes. However, on the ipsilateral temporal bone, the displacement magnitude decreased with increasing distance to the stimulation site, which indicated a wave-like motion around the BC loading position (Figure 14(c)). This shows that a fluctuation movement mode occurred around the excitation area in the excitation side of the skull surface. The contralateral temporal bone and nearby bone tissues demonstrated a rigid-body vibration, similar to the low-frequency case (Figure 14(d)).

At approximately $5000 \mathrm{~Hz}$, in the vicinity of the excitation region, the displacement magnitude decreased with increasing distance to the stimulation site, indicating a wavelike motion of the ipsilateral skull (Figure 14(e)). On the contralateral side of the skull, the displacement magnitude implied a superposition of multiple wave-like motions with different local centers (Figure 14(f)). This indicated that the rigid-body mode vibration of the skull surface was replaced with the superposition of multiple modes in high-frequency cases.

3.3. Transcranial Attenuation of the Temporal Bone by Scanning LDV and FE Model. The transcranial attenuation results of the temporal bone by FE model analysis and experiments are shown in Figure 15. With stimulation at the mastoid, the transcranial attenuation at low frequencies was approximately $0 \mathrm{~dB}, 3$ to $5 \mathrm{~dB}$ at frequencies up to $0.5 \mathrm{kHz}$, and approximately $0 \mathrm{~dB}$ between 0.5 and $1.8 \mathrm{kHz}$. The attenuation increased at higher frequencies; it was approximately $10 \mathrm{~dB}$ at 3 to $5 \mathrm{kHz}$ and became slightly less at the highest frequencies measured $(4 \mathrm{~dB}$ at $8 \mathrm{kHz})$. As shown in 


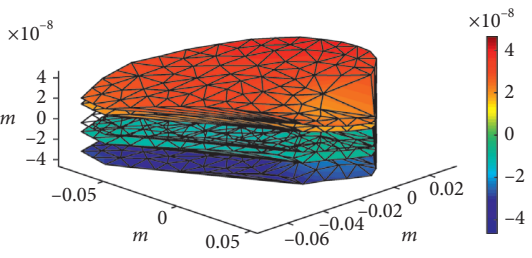

(a)

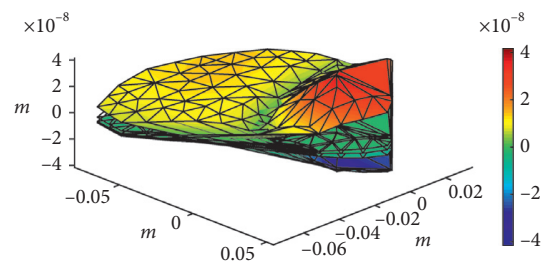

(d)

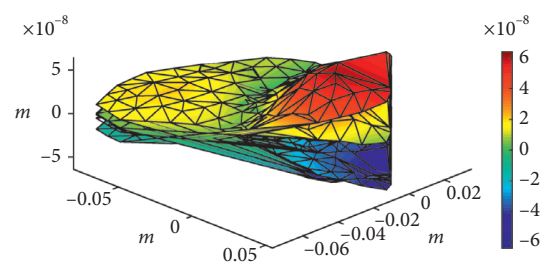

(g)

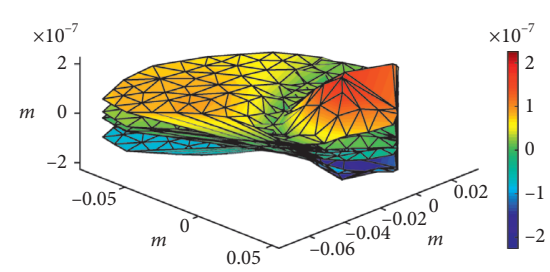

(b)

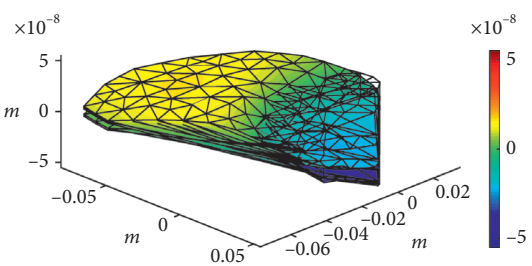

(e)

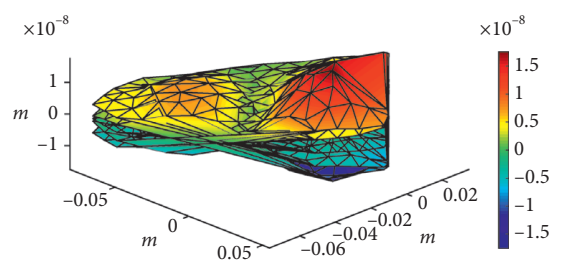

(h)

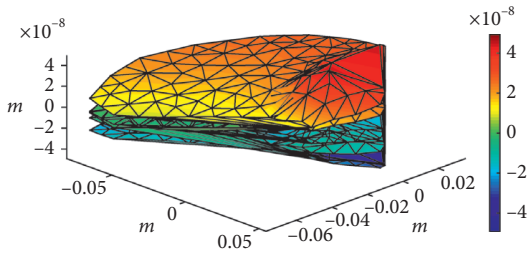

(c)

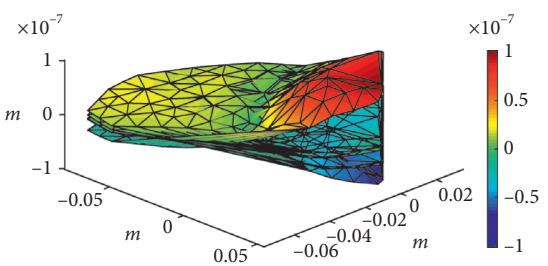

(f)

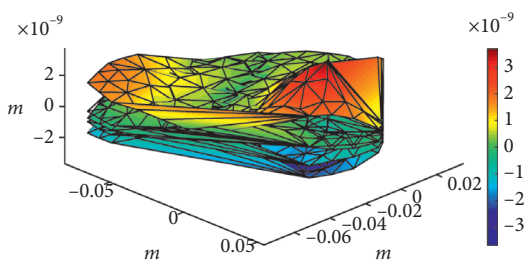

(i)

FIGURE 9: Vibration modes of the excitation side surface at the frequency of (a) $250 \mathrm{~Hz}$, (b) $500 \mathrm{~Hz}$, (c) $1000 \mathrm{~Hz}$, (d) $1500 \mathrm{~Hz}$, (e) $2000 \mathrm{~Hz}$, (f) $3000 \mathrm{~Hz},(\mathrm{~g}) 4000 \mathrm{~Hz}$, (h) $5000 \mathrm{~Hz}$, and (i) $6000 \mathrm{~Hz}$.

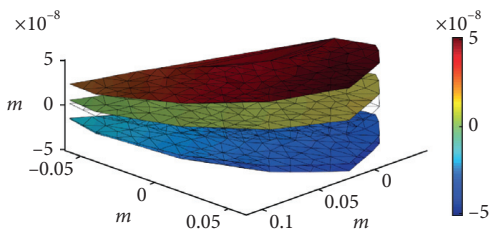

(a)

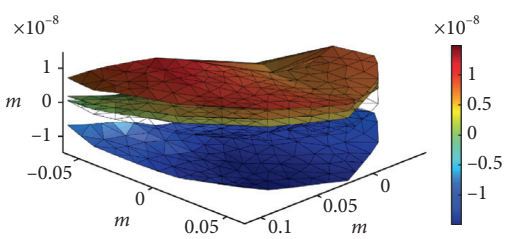

(d)

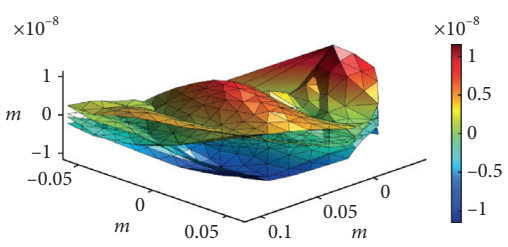

(g)

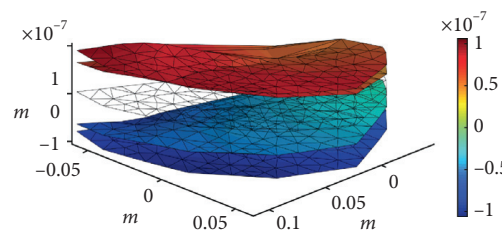

(b)

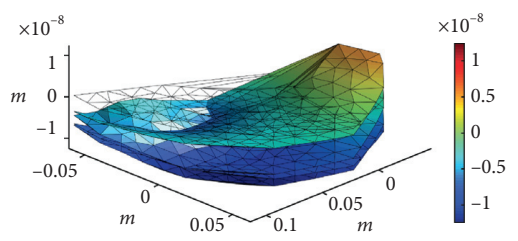

(e)

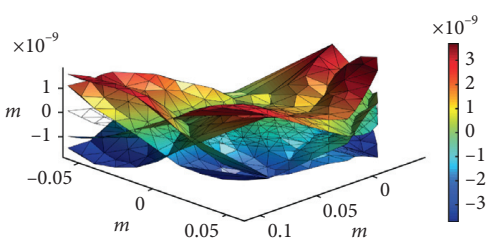

(h)

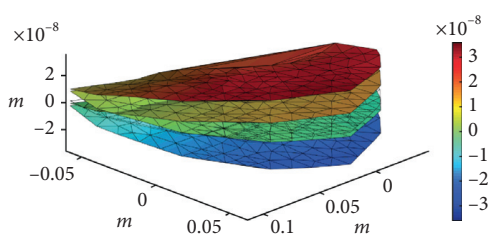

(c)

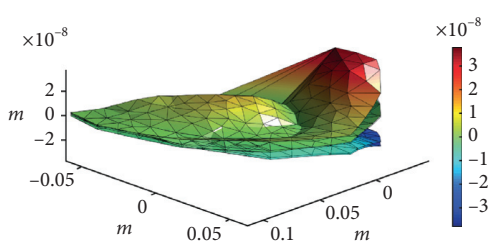

(f)

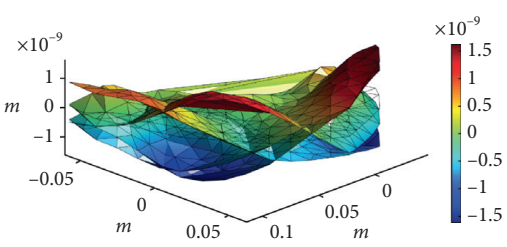

(i)

Figure 10: Vibration modes of the contralateral surface at the frequency of (a) $250 \mathrm{~Hz}$, (b) $500 \mathrm{~Hz}$, (c) $1000 \mathrm{~Hz}$, (d) $1500 \mathrm{~Hz}$, (e) $2000 \mathrm{~Hz}$, (f) $3000 \mathrm{~Hz},(\mathrm{~g}) 4000 \mathrm{~Hz}$, (h) $5000 \mathrm{~Hz}$, and (i) $6000 \mathrm{~Hz}$.

Figure 15, at frequencies below $1 \mathrm{kHz}$, the trend of the three curves is the same, and the first trough was formed at approximately $600 \mathrm{~Hz}$. At the 1 to $3 \mathrm{kHz}$ interval, the two curves varied widely, which could be attributed to the following reasons: a sponge was used in the experiment to support the skull specimens, the FE model had a fixed 


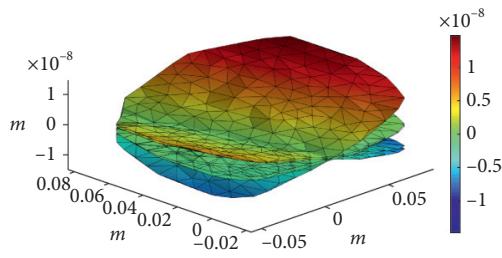

(a)

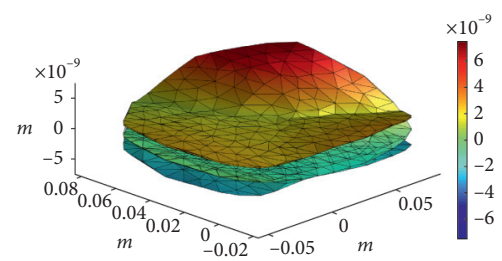

(d)

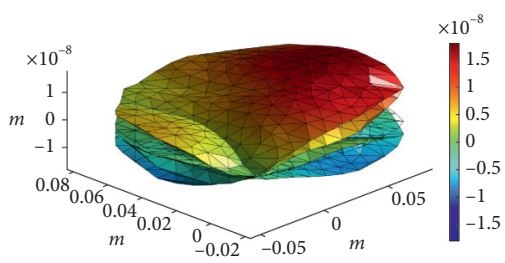

(g)

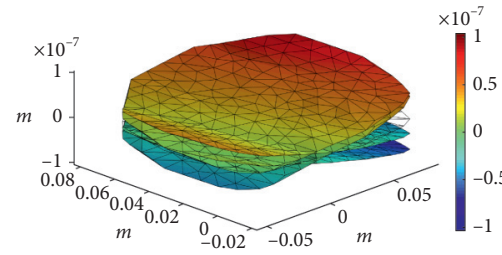

(b)

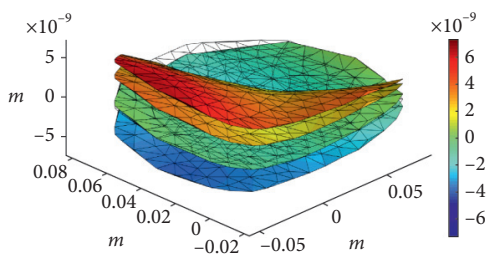

(e)

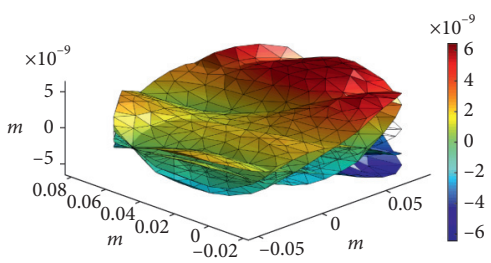

(h)

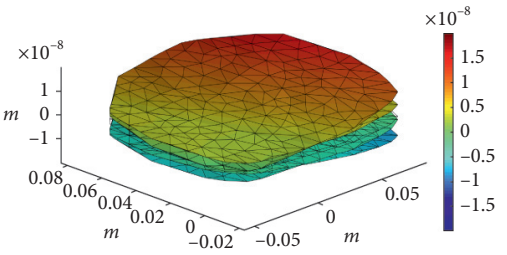

(c)

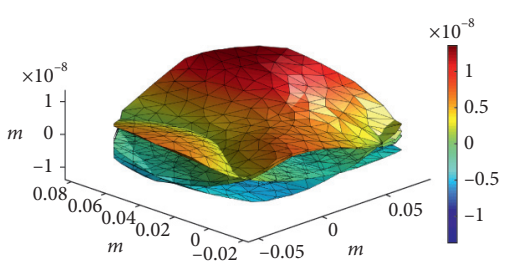

(f)

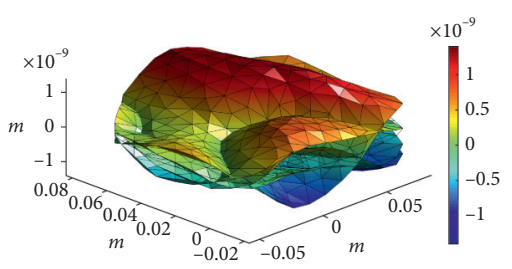

(i)

FiguRe 11: Vibration modes of the cranial roof surface at the frequency of (a) $250 \mathrm{~Hz}$, (b) $500 \mathrm{~Hz}$, (c) $1000 \mathrm{~Hz}$, (d) $1500 \mathrm{~Hz}$, (e) $2000 \mathrm{~Hz}$, (f) $3000 \mathrm{~Hz},(\mathrm{~g}) 4000 \mathrm{~Hz}$, (h) $5000 \mathrm{~Hz}$, and (i) $6000 \mathrm{~Hz}$.

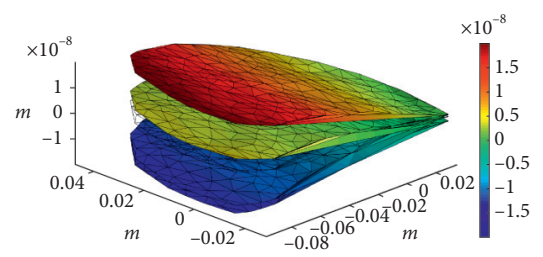

(a)

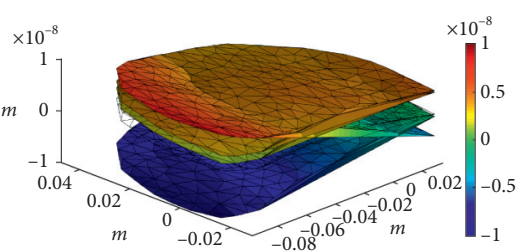

(d)

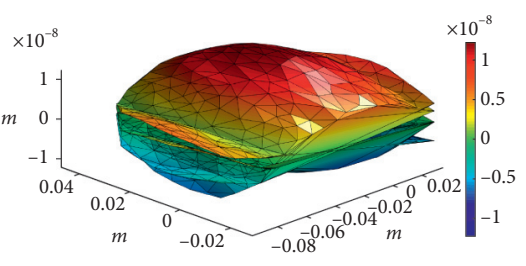

(g)

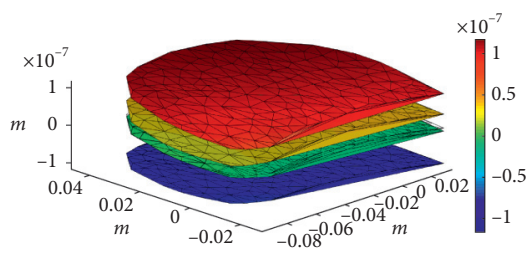

(b)

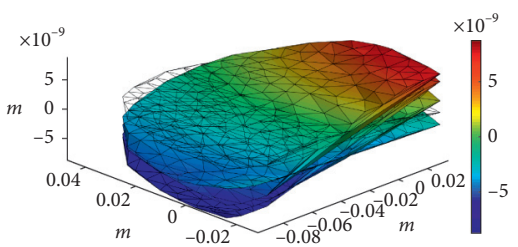

(e)

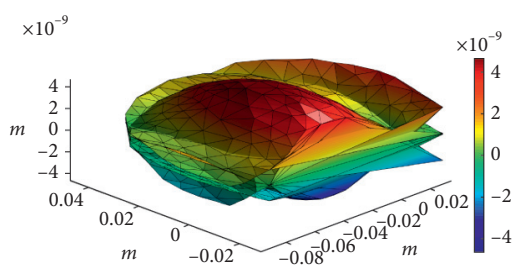

(h)

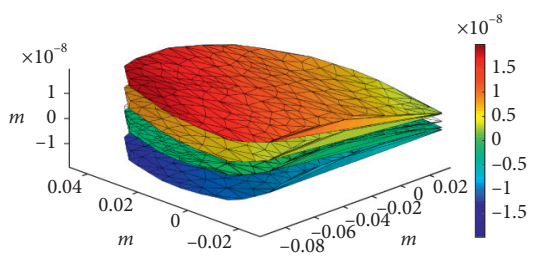

(c)

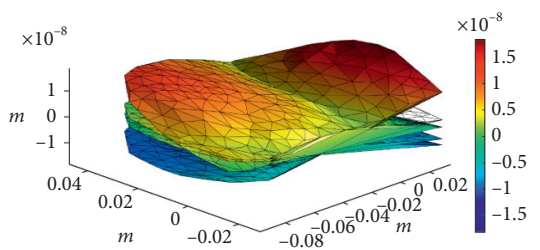

(f)

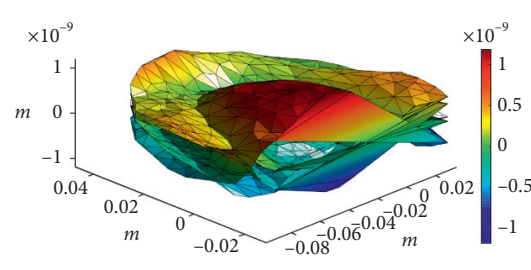

(i)

Figure 12: Vibration modes of the forehead surface at the frequency of (a) $250 \mathrm{~Hz}$, (b) $500 \mathrm{~Hz}$, (c) $1000 \mathrm{~Hz}$, (d) $1500 \mathrm{~Hz}$, (e) $2000 \mathrm{~Hz}$, (f) $3000 \mathrm{~Hz},(\mathrm{~g}) 4000 \mathrm{~Hz}$, (h) $5000 \mathrm{~Hz}$, and (i) $6000 \mathrm{~Hz}$. 


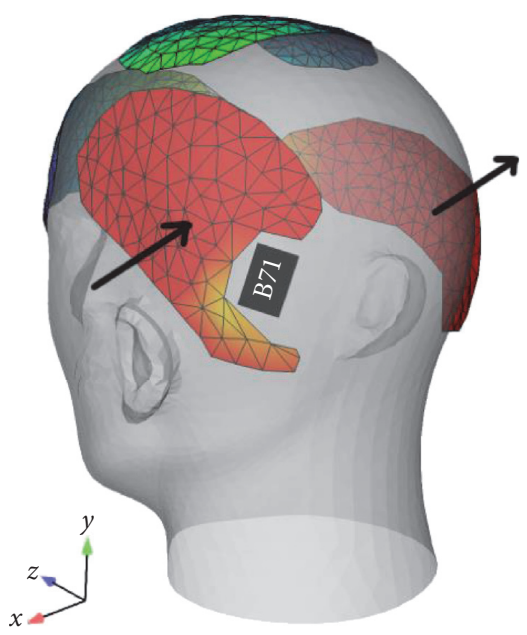

(a)

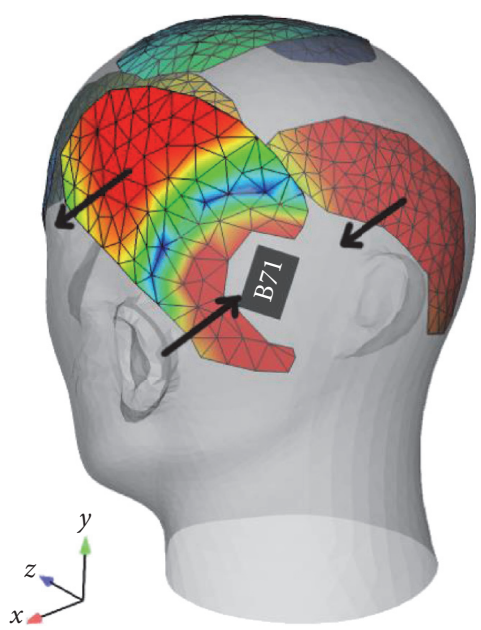

(b)

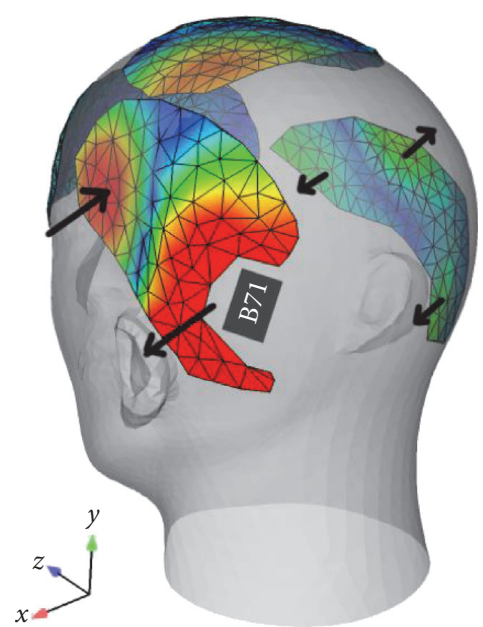

(c)

FIGURE 13: Experimental stimulation using a bone conduction transducer (B71 site) and results measured by LDV. Black arrows indicate the displacement direction. Colored legends represent the displacement magnitude, with red for the maximum value and blue for the minimum value. Each subfigure shows a (a) low frequency of $250 \mathrm{~Hz}$, (b) medium frequency of $1500 \mathrm{~Hz}$, and (c) high frequency of $5000 \mathrm{~Hz}$.

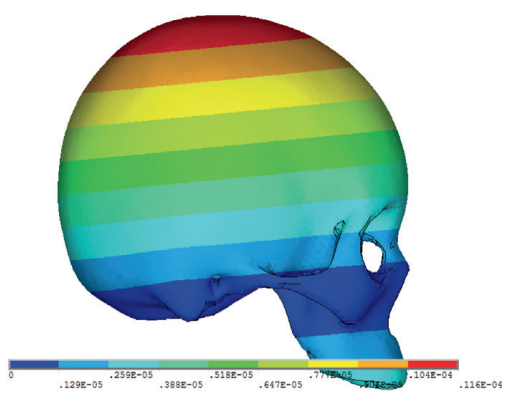

(a)

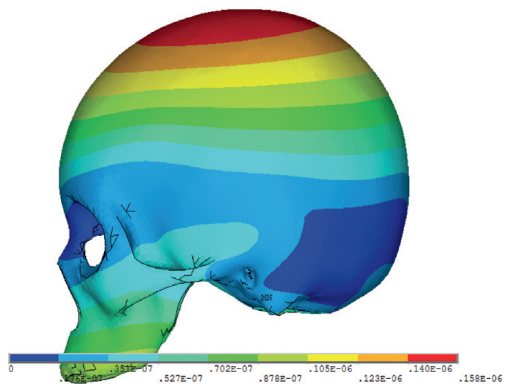

(d)

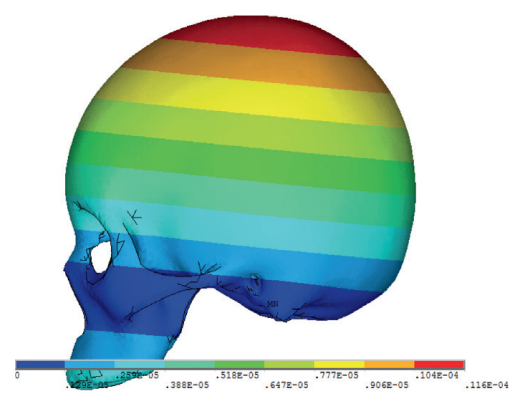

(b)

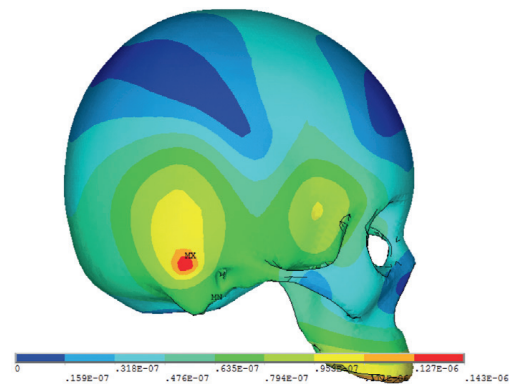

(e)

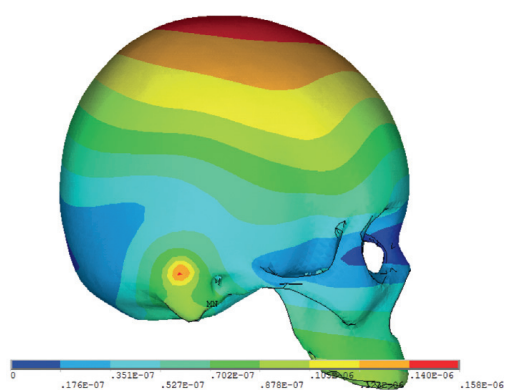

(c)

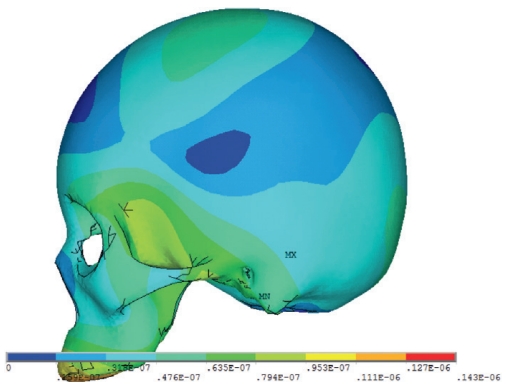

(f)

FIgURE 14: Magnitude of displacement of surface nodes on the ipsilateral and contralateral skull. Colored legend represented the magnitude of displacement (unit: $\mathrm{mm}$ ) at $X$ direction, where $X$ direction was defined as the ipsilateral-to-contralateral direction which was also the direction of BC stimulation. Each subfigure indicated (a) ipsilateral skull at $250 \mathrm{~Hz}$, (b) contralateral skull at $250 \mathrm{~Hz}$, (c) ipsilateral skull at $1500 \mathrm{~Hz},(\mathrm{~d})$ contralateral skull at $1500 \mathrm{~Hz}$, (e) ipsilateral skull at $5000 \mathrm{~Hz}$, and (f) contralateral skull at $5000 \mathrm{~Hz}$.

support boundary condition, and the skull fixation mode was not specified previously. The two curves changed in the larger range, but the basic trend fitted well. At high frequencies, the FE model and LDV measurement data fluctuated, with three peaks occurring at the same frequency values $(3,4$, and $5.5 \mathrm{kHz})$.
3.4. Transcranial Attenuation of the Middle Ear Structures by FE Model. The transcranial attenuations of the middle ear structures differed from that of the temporal bone in $\mathrm{BC}$ (Figure 16). In the low-frequency domain (below $300 \mathrm{~Hz}$ ), the transcranial attenuations were at the same level as the temporal bone, promontory, and stapes footplate, which 


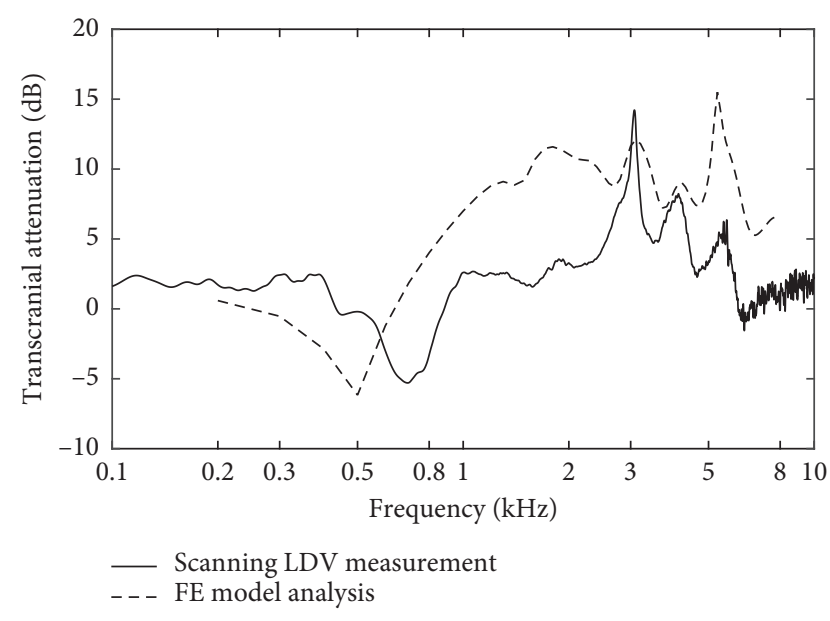

FIGURE 15: Transcranial attenuation of the temporal bone under BC stimulation from our experimental results and FE model. The transcranial attenuation was defined as $10 \log _{10} \mathrm{UX}_{1} / \mathrm{UX}_{2}$, where $\mathrm{UX}_{1}$ and $\mathrm{UX}_{2}$ represent the magnitudes of the $X$-direction displacement at the ipsilateral and contralateral temporal bone tissue nearby the stimulation site, respectively. The dashed line represents our multiscale whole human head FE model, and the solid line represents the LDV measurement.

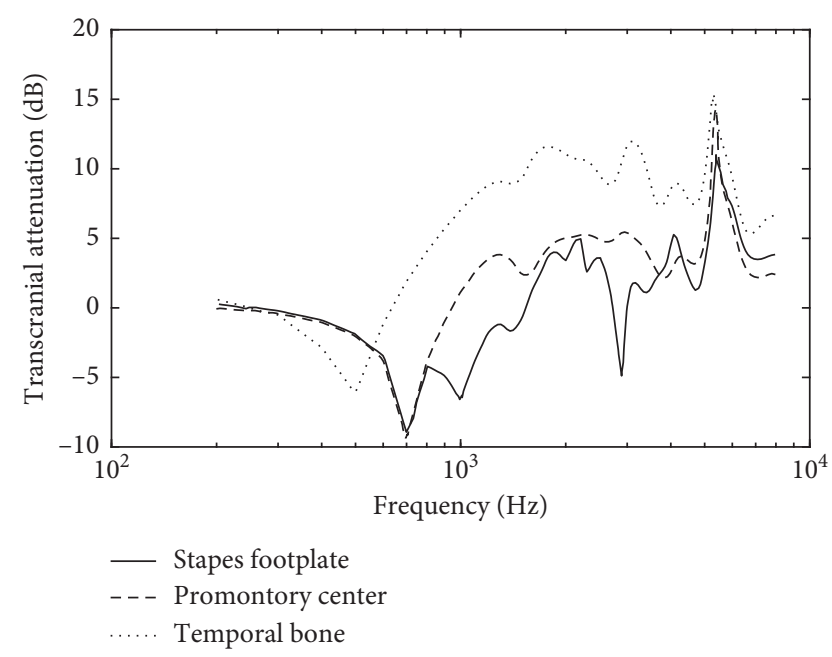

FIgURE 16: Transcranial attenuation of the temporal bone, promontory, and stapes footplate in $\mathrm{BC}$. The transcranial attenuation was defined as the $10 \log _{10} \mathrm{UX}_{1} / \mathrm{UX}_{2}$, where $\mathrm{UX}_{1}$ and $\mathrm{UX}_{2}$ represent the magnitudes of the $X$-direction displacement at the ipsilateral and contralateral sites, respectively. The displacement was evaluated at the temporal bone tissue nearby the $\mathrm{BC}$ stimulation site (dotted line), center of the stapes footplate (solid line), and center of the promontory (dashed line).

indicated that the rigid-body motion of the human skull dominated the vibrations of the entire structure. However, in the middle- and high-frequency domains $(0.7-4 \mathrm{kHz})$, the transcranial attenuation of the promontory and stapes footplate was $5-7 \mathrm{~dB}$ lower than that of the temporal bone. A lower transcranial attenuation implied that the ipsilateral vibration signal would be attenuated more on the contralateral temporal bone compared with that in the contralateral middle ear structure; hence, the measurements on the temporal bone would be insufficient to study the pathway of the middle ear structure in the $\mathrm{BC}$ mechanism. Additionally, the transcranial attenuations of the promontory and stapes footplate showed different antiresonance and resonance frequencies, indicating that the middle ear structure might contribute to the $\mathrm{BC}$ mechanism.

3.5. Relative Importance of the Middle Ear Pathway in BC. To study the role of the ossicular chain in $\mathrm{BC}$, the mean values of the relative movement of the tympanic membrane amplitude to the external auditory canal and the relative movement of the stapes footplate amplitude to the adjacent bone were obtained. As shown in Figure 17, as the frequency increased under BC stimulation from 200 to $700 \mathrm{~Hz}$, the relative motion curves of the tympanic membrane and stapes reduced monotonically. At $700-2000 \mathrm{~Hz}$, the tympanic membrane curve exhibited a peak, while the stapes footplate did not; a slow decline was observed after a platform period.

The trend of relative displacement of the TM and stapes footplate indicated that the inertial force of the middle ear structure contributed to the $\mathrm{BC}$ in the low- and middlefrequency ranges. The relative displacement of the TM showed more antiresonance and resonance frequencies compared with the relative displacement of the stapes footplate because the fluid impendence boundary condition would constrain the vibration of the stapes footplate, whereas the TM could vibrate owing to the inertial force of the middle ear structures. At frequencies above $2000 \mathrm{~Hz}$, the two curves were gentler and several peaks and valleys appear. The resonance located at $1600 \mathrm{~Hz}$ showed the most distinct difference between the two relative displacements, implying the resonance frequency of the middle ear structure under $\mathrm{BC}$ stimulation. The inertia of the ossicular chain is one of the methods of $\mathrm{BC}$, especially in the low- and middle-frequency ranges.

3.6. Relative Importance of the Inner Ear Pathway in BC. The relative displacement of the inner structures demonstrated a similar trend under the BC stimulation (Figure 18). The relative displacements of the first and second turns in the cochlea and those of the semicircular canals to vestibular were below 0.5 in the low-frequency domain $(200-500 \mathrm{~Hz})$ and showed that the movement of the inner structure was dominated by translation instead of volume alternation. In the middle-frequency domain $(1-4 \mathrm{kHz})$, the relative displacements of the first and second turns in the cochlea increased to approximately one, while those of the semicircular canals increased to approximately 1.5 . The increased relative displacements of the three components indicated that the expansion and compression movements of the inner ear structure might contribute to $\mathrm{BC}$ in the middle-frequency range. In the high-frequency range, multiple resonance and antiresonance frequencies appeared for all components, rendering it difficult to obtain any insightful conclusion. 


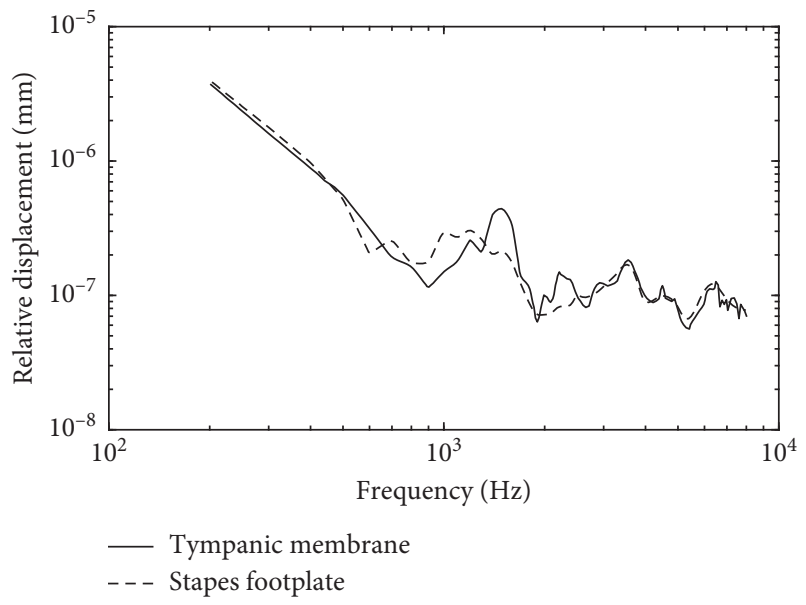

FIGURE 17: Relative displacement of the TM and stapes footplate in BC. The relative displacement of the TM (solid line) was evaluated by subtracting the displacement magnitude (3D displacement magnitude) of the nearby bony outer ear canal from the displacement magnitude of the center of the TM. The relative displacement of the stapes footplate (dashed line) was evaluated by subtracting the displacement magnitude of the center of the promontory from that of the center of the stapes footplate.

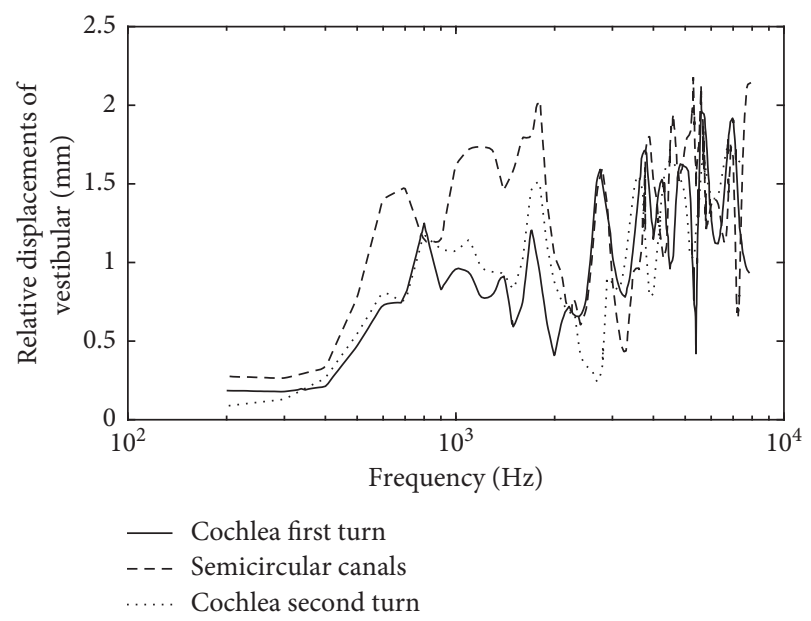

FIGURE 18: Relative displacements (to the vestibular) of the first turn in the cochlea (solid line), second turn in the cochlea (dotted line), and semicircular canals (dashed line) in BC. The relative displacement (to the vestibular) was evaluated as the ratio of difference in displacement magnitude (3D displacement magnitude) of a component and that of the vestibular, over the displacement magnitude of the vestibular.

\section{Discussion}

4.1. Further Investigation of Middle and Inner Ear Contribution to BC by Whole-Head FE Model. A new multiscale human whole-head FE model is proposed herein, which includes the bony outer ear, ossicular chains, and bony inner ear structures, to study the BC mechanism of the human hearing system. For comparative analysis between FE model and experimental studies, the outer skin was not included, which can absorb BC energy, thus reducing vibration response amplitudes of the skull. Using the multiscale human whole-head FE model, we illustrate the frequency range at which the middle and inner ear structures contribute to the $\mathrm{BC}$, as well as the frequency response of the TM and stapes footplate.

The transcranial attenuation of the skull, promontory, and stapes footplate implied that the transcranial transmission efficiencies were distinct for the skull and middle ear structure. Hence, measuring (experiments) or calculating (FE models) the transcranial attenuation at the surface of the skull would be inadequate to study the contribution of the middle ear structure in the $\mathrm{BC}$ mechanism. The multiscale human whole-head FE model, compared with previous FE models which focused on the human skull and surrounding soft tissues $[25,26,33]$, was embedded with the miniature middle ear and inner ear structures. Therefore, the new FE model could provide more direct measurements of the frequency responses of the ipsilateral and contralateral TM or stapes footplate, which was strongly associated with the perception of the $\mathrm{BC}$ sound.

The multiscale human whole-head FE model suggested that the inertial force of the middle ear structure contributed to $\mathrm{BC}$ at low and middle frequencies (less than $1 \mathrm{kHz}$ ). It also indicated that the translation movement of the inner ear structure contributed to $\mathrm{BC}$ at low frequencies $(200-500 \mathrm{~Hz})$, whereas the alternation of the inner ear volume contributed to $\mathrm{BC}$ at high frequencies $(1-4 \mathrm{kHz})$. The contribution of various pathways in the $\mathrm{BC}$ was primarily consistent with reported values, in which the inertial force of the ossicles was regarded as important at frequencies $2 \mathrm{kHz}$ and below, and the alternation of the cochlear space was regarded as effective at approximately $4 \mathrm{kHz}[1,22]$. The consistency implied that the multiscale human whole-head FE model could demonstrate the relative importance of other pathways in $\mathrm{BC}$, which might be difficult or impossible to measure owing to ethical reasons or experimental complexity.

The multiscale human whole-head FE model of this study still has some limitations. Because the inner ear lymph is not included, the effects of the fluid to the ossicles were equivalent to the spring-mass-damping system acting on stapes footplate. The addition of inner ear lymph fluid required the fluid-structure interaction between the lymph fluid and the bony labyrinth, the stapes footplate, and the basal membrane, which was needed to further investigate responses of the lymph fluid and basal membrane under BC.

4.2. Relationship between Vibration Modes and Transcranial Attenuation Characteristics of Human Whole Head. In previous laboratory studies, transcranial attenuation has been measured using two methods: 1D surface measurements [9, 34] and 3D surface measurements [14]. The 1D measurements yield the motion information along the selected direction; however, by the 3D measurements, the movement information in all the spatial directions in space is obtained. Theoretically, when the object is moving as an entire body, the 1D measurement results along the motion 


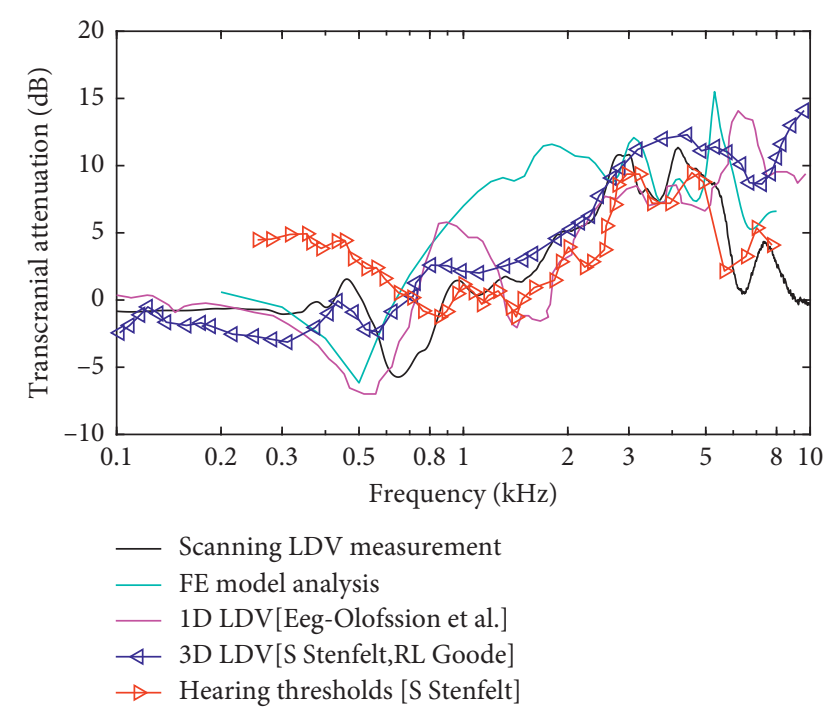

Figure 19: Transcranial attenuation results measured by (1) scanning LDV of this study (black line), (2) FE model of this study (green line), (3) 1D LDV measurement of studies of Eeg-Olofsson et al. [9] (pink line), (4) 3D LDV measurement of studies of Stenfelt and Goode [14](blue triangle line), and (5) hearing thresholds of studies by Stenfelt [18] (red triangle line).

direction is similar to the $3 \mathrm{D}$ results. However, when a wavy motion occurs, the results will be distinct. Additionally, in the clinic, BC transcranial attenuation is typically obtained by $\mathrm{BC}$ threshold measurements in pure tone audiometry $[13,17,18]$.

As shown in Figure 19, in the low-frequency range under $400 \mathrm{~Hz}$, the $1 \mathrm{D}$ transcranial attenuation results are consistent with those of $3 \mathrm{D}$, and they were both approximately $0 \mathrm{~dB}$. This was because of the rigid body motion of the skull in the excitation direction, as indicated in Figures 13(a), 14(a), and 14(b).

In the low-middle frequencies range $(400-900 \mathrm{~Hz})$, the $1 \mathrm{D}$ transcranial attenuation results were negative; in other words, the motion amplitude in the contralateral surface was more significant than that at the excitation side. The value first decreased to approximately $-5 \mathrm{~dB}$ and subsequently increased to approximately $0 \mathrm{~dB}$. As shown by the experimental and FE model analyses as illustrated in Figures 13(b), 14(c), and 14(d), on the excitation side of the head, the temporal bone's vibration modes gradually transformed from a rigid body to a wave-like form, while the contralateral side still indicated a rigid-body movement. Therefore, when measuring the movement amplitude by $1 \mathrm{D}$ LDV, the amplitude of the excitation side was underestimated. Hence, the transcranial attenuation was negative. The 3D transcranial attenuation was approximately $0 \mathrm{~dB}$. The sum of the three directional components has been calculated; however, compared with the auditory results (approximately $2-5 \mathrm{~dB}$ ), the total energy attenuation that ultimately produced auditory perception was not reflected because the middle and inner ear contributions to BC were not included $[19,22]$.

In the middle-high frequency range, the rigid-body motion in the contralateral side decreased, and the wavy motion began to emerge and promoted gradually. The 1D and $3 \mathrm{D}$ transcranial attenuation results were positive and increased gradually. The audiometry transcranial attenuation results first decreased to approximately $2 \mathrm{~dB}$, slightly less than the dynamical results. Subsequently, the three results were consistent, and with the increase in frequency, they exhibited the same upward trend.

\section{Conclusion}

In this study, experimental and numerical studies on wholehead vibration modes and transcranial attenuation characteristics in BC were performed. By scanning LDV measurement on human cadaver head and FE analysis of a multiscale human whole-head model including the skull, the bony outer ear, the ossicular chains, and the bony inner ear structures, this research revealed the frequency dependence of BC vibration modes of the whole head, the contribution of middle and inner ear pathways to $\mathrm{BC}$ hearing, and the relationship between transcranial attenuation results by dynamics measurement and hearing thresholds. Based on the results of experimental studies and numerical simulations, the corresponding conclusions can be concluded as follows:

(1) As the frequency increased, the whole-head vibration modes changed from simple rigid motions to sophisticated local compression. Moreover, more fluctuations appeared on the excitation side than on the contralateral side.

(2) The FE analysis results showed that the inertia force of the ossicular chain was critical in BC at the lowmiddle frequency. Additionally, the frequency responses of the stapes and TM were affected by the dynamic characteristics of the ossicular chain, whose resonance appeared at the frequency of approximately $1600 \mathrm{~Hz}$.

(3) The transcranial attenuation results of the temporal bone showed an overall upward trend except at the middle frequency (approximately $700 \mathrm{~Hz}$ ). This was because the excitation position and the adjacent region exhibited opposite phase motions, whereas the contralateral side exhibited the same phase, thereby resulting in a negative value.

\section{Data Availability}

The data used to support the findings of this study are available from the corresponding author upon request.

\section{Conflicts of Interest}

The authors declare that they have no conflicts of interest.

\section{Acknowledgments}

This research was supported by the National Natural Science Foundations of China (Grant no. 81771014) and Key Project of National Natural Science Foundation of China (Grant no. 11932010). The support is greatly appreciated. 


\section{References}

[1] R. Dauman, "Bone conduction: an explanation for this phenomenon comprising complex mechanisms," European Annals of Otorhinolaryngology, Head and Neck Diseases, vol. 130, no. 4, pp. 209-213, 2013.

[2] S. Puria and J. J. Rosowski, "Békésy's contributions to our present understanding of sound conduction to the inner ear," Hearing Research, vol. 293, no. 1-2, pp. 21-30, 2012.

[3] J. Dumper, B. Hodgetts, R. Liu, and N. Brandner, "Indications for bone-anchored hearing aids: a functional outcomes study," Journal of Otolaryngology-Head \& Neck Surgery, vol. 38, no. 1, p. 96, 2009.

[4] G. Ricci, A. D. Volpe, M. Faralli et al., "Bone-anchored hearing aids (Baha) in congenital aural atresia: personal experience," International Journal of Pediatric Otorhinolaryngology, vol. 75, no. 3, pp. 342-346, 2010.

[5] J. J. Wazen, J. Spitzer, S. N. Ghossaini, A. Kacker, and A. Zschommler, "Results of the bone-anchored hearing aid in unilateral hearing loss," The Laryngoscope, vol. 111, no. 6, pp. 955-958, 2001.

[6] J. L. Danhauer, C. E. Johnson, and M. Mixon, "Does the evidence support use of the Baha implant system (Baha) in patients with congenital unilateral aural atresia?" Journal of the American Academy of Audiology, vol. 21, no. 4, pp. 274286, 2010.

[7] R. W. J. McLeod, J. F. Culling, and D. Jiang, "Advances in the field of bone conduction hearing implants," Advances in OtoRhino-Laryngology, vol. 81, pp. 24-31, 2018.

[8] C. Röösli, D. Chhan, C. Halpin, and J. J. Rosowski, "Comparison of umbo velocity in air- and bone-conduction," Hearing Research, vol. 290, no. 1-2, pp. 83-90, 2012.

[9] M. Eeg-Olofsson, S. Stenfelt, and G. Granström, "Implications for contralateral bone-conducted transmission as measured by cochlear vibrations," Otology \& Neurotology, vol. 32, no. 2, pp. 192-198, 2011.

[10] G. R. Popelka, G. Telukuntla, and S. Puria, "Middle-ear function at high frequencies quantified with advanced boneconduction measures," Hearing Research, vol. 263, no. 1-2, pp. 85-92, 2010.

[11] R. Perez, C. Adelman, and H. Sohmer, "Bone conduction activation through soft tissues following complete immobilization of the ossicular chain, stapes footplate and round window," Hearing Research, vol. 280, no. 1-2, pp. 82-85, 2011.

[12] D. Chhan, C. Röösli, M. L. McKinnon, and J. J. Rosowski, "Evidence of inner ear contribution in bone conduction in chinchilla," Hearing Research, vol. 301, pp. 66-71, 2013.

[13] H. A. Snapp, K. E. Morgenstein, F. F. Telischi, and S. Angeli, "Transcranial attenuation in patients with single-sided deafness," Audiology and Neurotology, vol. 21, no. 4, pp. 237-243, 2016.

[14] S. Stenfelt and R. L. Goode, "Transmission properties of bone conducted sound: measurements in cadaver heads," The Journal of the Acoustical Society of America, vol. 118, no. 4, pp. 2373-2391, 2005.

[15] J. D. Hood, "The principles and practice of bone conduction audiometry: a review of the present position," The Laryngoscope, vol. 70, no. 9, pp. 1211-1228, 1960.

[16] D. W. Robinson and M. S. Shipton, "A standard determination of paired air- and bone-conduction thresholds under different masking noise conditions," International Journal of Audiology, vol. 21, no. 1, pp. 61-82, 1982.

[17] T. Ito, C. Röösli, C. J. Kim, J. H. Sim, A. M. Huber, and R. Probst, "Bone conduction thresholds and skull vibration measured on the teeth during stimulation at different sites on the human head," Audiology and Neurotology, vol. 16, no. 1, pp. 12-22, 2010.

[18] S. Stenfelt, "Transcranial attenuation of Bone-conducted sound when stimulation is at the mastoid and at the bone conduction hearing aid position," Otology \& Neurotology, vol. 33, no. 2, pp. 105-114, 2012.

[19] K. Homma, Y. Du, Y. Shimizu, and S. Puria, "Ossicular resonance modes of the human middle ear for bone and air conduction," The Journal of the Acoustical Society of America, vol. 125, no. 2, pp. 968-979, 2009.

[20] H. Sohmer, S. Freeman, and R. Perez, "Semicircular canal fenestration - improvement of bone- but not air-conducted auditory thresholds," Hearing Research, vol. 187, no. 1-2, pp. 105-110, 2004.

[21] N. Kim, K. Homma, and S. Puria, "Inertial bone conduction: symmetric and anti-symmetric components," Journal of the Association for Research in Otolaryngology, vol. 12, no. 3, pp. 261-279, 2011.

[22] S. Stenfelt, F. N. O. I. Avdelningen, F. Medicinska, U. Linköpings, and F. K. O. E. Institutionen, "Inner ear contribution to bone conduction hearing in the human," Hearing Research, vol. 329, pp. 41-51, 2015.

[23] A. Arani, M. C. Murphy, K. J. Glaser et al., "Measuring the effects of aging and sex on regional brain stiffness with MR elastography in healthy older adults," NeuroImage, vol. 111, pp. 59-64, 2015.

[24] T. W. Barber, J. A. Brockway, and L. S. Higgins, "The density of tissues in and about the head," Acta Neurologica Scandinavica, vol. 46, no. 1, pp. 85-92, 1970.

[25] M. K. Brummund, F. Sgard, Y. Petit, and F. Laville, "Threedimensional finite element modeling of the human external ear: simulation study of the bone conduction occlusion effect," The Journal of the Acoustical Society of America, vol. 135, no. 3, pp. 1433-1444, 2014.

[26] N. Kim, Y. Chang, S. Stenfelt et al., "A three-dimensional finite-element model of a human dry skull for bone-conduction hearing," Biomed Research International, vol. 2014, Article ID 519429, 2014.

[27] R. Z. Gan, B. Feng, and Q. Sun, "Three-dimensional finite element modeling of human ear for sound transmission," Annals of Biomedical Engineering, vol. 32, no. 6, pp. 847-859, 2004.

[28] Y. Zhu, L. Chen, T. Zhang et al., "Equivalent model of cochlear lymph fluid in middle ear finite element analysis," Journal of Vibration and Shock, vol. 29, no. 7, pp. 79-82, 2010.

[29] B. E. V. Håkansson, "The balanced electromagnetic separation transducer: a new bone conduction transducer," The Journal of the Acoustical Society of America, vol. 113, no. 2, pp. 818-825, 2003.

[30] K.-J. F. Jansson, B. Håkansson, L. Johannsen, and T. Tengstrand, "Electro-acoustic performance of the new bone vibrator Radioear B81: a comparison with the conventional Radioear B71," International Journal of Audiology, vol. 54, no. 5, pp. 334-340, 2015.

[31] S. Stenfelt, B. Håkansson, and A. Tjellström, "Vibration characteristics of bone conducted soundin vitro," The Journal of the Acoustical Society of America, vol. 107, no. 1, pp. 422-431, 2000.

[32] S. Stenfelt, N. Hato, and R. L. Goode, "Factors contributing to bone conduction: the middle ear," The Journal of the Acoustical Society of America, vol. 111, no. 2, pp. 947-959, 2002. 
[33] H. Taschke and H. Hudde, "A finite element model of the human head for auditory bone conduction simulation," Orl, vol. 68, no. 6, pp. 319-323, 2006.

[34] C. Rigato, S. Reinfeldt, B. Håkansson, K.-J. Fredén Jansson, E. Renvall, and M. Eeg-Olofsson, "Direct bone conduction stimulation: ipsilateral effect of different transducer attachments in active transcutaneous devices," Hearing Research, vol. 361, pp. 103-112, 2018. 